\title{
Dual Transcriptional Profiling of Carrot and 'Candidatus Liberibacter solanacearum' at Different Stages of Infection Suggests Complex Host-Pathogen Interaction
}

\author{
Jinhui Wang, ${ }^{1}$ Minna Haapalainen, ${ }^{1}$ Anne I. Nissinen, ${ }^{2}$ and Minna Pirhonen ${ }^{1, \dagger}$ \\ ${ }^{1}$ University of Helsinki, Department of Agricultural Sciences, P. O. Box 27, FI-00014 University of Helsinki, Finland \\ ${ }^{2}$ Natural Resources Institute Finland (Luke), Natural Resources, Tietotie 2C, FI-31600 Jokioinen, Finland
}

Accepted 22 July 2021.

The interactions between the phloem-limited pathogen 'Candidatus Liberibacter solanacearum' haplotype $C$ and carrot (Daucus carota subsp. sativus) were studied at 4, 5, and 9 weeks postinoculation (wpi), by combining dual RNASeq results with data on bacterial colonization and observations of the plant phenotype. In the infected plants, genes involved in jasmonate biosynthesis, salicylate signaling, pathogen-associated molecular pattern- and effector-triggered immunity, and production of pathogenesis-related proteins were up-regulated. At 4 wpi, terpenoid synthesis-related genes were up-regulated, presumably as a response to the psyllid feeding, whereas at 5 and 9 wpi, genes involved in both the terpenoid and flavonoid production were down-regulated and phenylpropanoid genes were up-regulated. Chloroplast-related gene expression was down-regulated, in concordance with the observed yellowing of the infected plant leaves. Both the RNA-Seq data and electron microscopy suggested callose accumulation in the infected phloem vessels, likely to impair the transport of photosynthates, while phloem regeneration was suggested by the formation of new sieve cells and the upregulation of cell wall-related gene expression. The ' $\mathrm{Ca}$. L. solanacearum' genes involved in replication, transcription, and translation were expressed at high levels at 4 and 5 wpi, whereas, at 9 wpi, the Flp pilus genes were highly expressed, suggesting adherence and reduced mobility of the bacteria. The ' $\mathrm{Ca}$. L. solanacearum' genes encoding ATP and C4-dicarboxylate uptake were differentially

${ }^{\dagger}$ Corresponding author: M. Pirhonen; minna.pirhonen@helsinki.fi

Current address for J. Wang: College of Plant Protection, Hebei Agricultural University, Lekai South Street 2596, Baoding 071001 Hebei, China.

The first two authors made equal contributions to this work.

The raw RNA-Seq datasets have been deposited at the sequence read archive of the National Center for Biotechnology Information under the project number PRJNA574412.

Funding: The work was funded by the Niemi Foundation, China Scholarship Council, Finland Ministry of Agriculture and Forestry grant 1842/03.01.02/2013, the Future Fund of University of Helsinki, and the Marjatta \& Eino Kolli Foundation. Open access funded by Helsinki University Library.

*The $\boldsymbol{e}$-Xtra logo stands for "electronic extra" and indicates there are supplementary materials published online.

The author(s) declare no conflict of interest. distributed under the CC BY-NC-ND 4.0 International license. expressed between the early and late infection stages, suggesting a change in the dependence on different host-derived energy sources. HPE1 effector and salicylate hydroxylase were expressed, presumably to suppress host cell death and salicylic aciddependent defenses during the infection.

Keywords: Daucus carota, dual RNA-Seq, plant hormones, plant-pathogen interactions, Trioza apicalis

Many cultivated plants suffer from diseases transmitted by insect vectors, and carrot (Daucus carota subsp. sativus) is not an exception. Carrot psyllids (Trioza apicalis) cause substantial damage when feeding on the carrot leaves, and in addition to this damage, the psyllids also harbor and transmit a bacterial pathogen called 'Candidatus Liberibacter solanacearum' (Munyaneza et al. 2010; Nissinen et al. 2007, 2012, 2014). 'Ca. L. solanacearum' is associated with several different plant diseases over a wide geographic distribution (Haapalainen 2014; Liefting et al. 2009; N. Wang et al. 2017) and, so far, 10 distinct haplotypes of ' $\mathrm{Ca}$. L. solanacearum' have been identified. The haplotypes A, B, and $\mathrm{F}$ have been associated with zebra chip disease of potato (Solanum tuberosum) in the United States, haplotypes A and B in Mexico and haplotype A in Central America and in New Zealand (Nelson et al. 2011; Swisher Grimm and Garczynski 2019; Thompson et al. 2015). The tomato potato psyllid Bactericera cockerelli Sulc was identified as the vector for haplotypes A and B (Hansen et al. 2008; Nelson et al. 2011). Haplotype G, which is closely related to haplotype F, was identified from a wild solanaceous species, Solanum umbelliferum, using museum herbarium samples (Mauck et al. 2019). In Europe, haplotypes C, D, and $\mathrm{E}$ cause diseases on several apiaceous crops, including carrot and celery (Hajri et al. 2017; Munyaneza et al. 2010; Teresani et al. 2014). In northern Europe, ' $\mathrm{Ca}$. L. solanacearum' haplotype C is transmitted by T. apicalis Förster (Nissinen et al. 2014), and in the Mediterranean area, the haplotypes D and E are transmitted by Bactericera trigonica Hodkinson, feeding on both carrot and celery (Antolinez et al. 2017). Haplotype H was recently identified and found to infect both the apiaceous plants carrots and parsnips and the Polygonaceae family plant species Fallopia convolvulus and Persicaria lapathifolia (Haapalainen et al. 2020). Haplotypes Cras1 and Cras2, closely related to haplotype $\mathrm{H}$, were found in Craspedolepta spp. psyllids in Scotland (Sumner-Kalkun et al. 2020). Haplotype U, found in the wild plant species Urtica dioica and the psyllid T. urticae (Haapalainen et al. 2018), has not been reported in cultivated plants.

Typical symptoms observed in carrots infected with ' $\mathrm{Ca}$. L. solanacearum' haplotype C include the symptoms caused by 
the carrot psyllid T. apicalis feeding, leaf curling, and stunted growth of the shoot and root and the symptoms associated with the bacterial infection, leaf discoloration and reduced storage root weight (Nissinen et al. 2014). The psyllid-induced leaf curling is a rapid response, whereas the ' $\mathrm{Ca}$. L. solanacearum'-associated symptoms develop slowly and become visible 1.5 months after inoculation, when the bacterial titer is high (Nissinen et al. 2014, 2020). Proliferation of shoots or roots was not related to ' $\mathrm{Ca}$. L. solanacearum' haplotype $\mathrm{C}$ infection in field-grown carrots (Haapalainen et al. 2017), whereas these symptoms are prominent in carrots and other apiaceous plants infected with the haplotypes $D$ and $E$ (Hajri et al. 2017).

The first genome sequences of the unculturable ' $\mathrm{Ca}$. Liberibacter' species were obtained from ' $\mathrm{Ca}$. L. asiaticus', the causal agent of citrus huanglongbing disease, and from ' $\mathrm{Ca}$. L. solanacearum' haplotype $\mathrm{B}$, associated with zebra chip disease of potato (Duan et al. 2009; Lin et al. 2011). The bacterial DNA for sequencing was derived from the psyllids Diaphorina citri and B. cockerelli, for ' $\mathrm{Ca}$. L. asiaticus' and ' $\mathrm{Ca}$. L. solanacearum', respectively, due to the low relative titers of these bacteria in the plants. The first transcriptomic studies on plants infected with ' $\mathrm{Ca}$. L. solanacearum' were performed on potato, revealing differences in gene expression profiles between potato varieties showing different disease severity of zebra chip (Levy et al. 2017) and between different parts of the potato plant (Nwugo et al. 2017). The detected physiological changes in potato plant in response to ' $\mathrm{Ca}$. L. solanacearum' shed light on the molecular mechanisms of zebra chip disease development. Recent studies showed that the populations of $B$. cockerelli and Diaphorina citri that harbor or do not harbor ' $\mathrm{Ca}$. $\mathrm{L}$. solanacearum' or 'Ca. L. asiaticus', respectively, elicit different responses in their host plants (Huot et al. 2018; Nehela et al. 2018). The results suggest that Liberibacter infection modulates the ability of the host to respond to psyllid herbivory.

To uncover the interactions between ' $\mathrm{C}$. L. solanacearum' and the host plant, gene expression data of both the bacteria and the infected plant are required. However, genome-wide transcriptome profiling of a phloem-restricted pathogen in plant is technically very challenging, as the bacterial mRNA constitutes a minor fraction of the total mRNA, especially at the early stage of infection when the bacterial titer is low. For ' $\mathrm{Ca}$. L. asiaticus', a large-scale study on bacterial gene expression changes related to the host transition between the plant and psyllid was performed using real-time PCR on 381 genes, which represent a third of the total protein-coding genes in the ' $\mathrm{Ca}$. L. asiaticus' genome (Yan et al. 2013). Thus far, the transcriptome of ' $\mathrm{Ca}$. L. solanacearum' has only been studied on the psyllid host $B$. cockerelli. When the gene expression of the two ' $\mathrm{Ca}$. L. solanacearum' haplotypes A and B in B. cockerelli were compared, four of the potentially secreted protein genes (putative effectors) were found differentially expressed (Yao et al. 2016). The highly expressed genes of the ' $\mathrm{Ca}$. L. solanacearum' haplotypes $\mathrm{A}$ and $\mathrm{B}$ were recognized as genes required for maintaining the basic functions of the bacterial cells (Ibanez et al. 2014; Yao et al. 2016). Before the present study, no transcriptome analysis has been reported for ' $\mathrm{Ca}$. L. solanacearum' in a plant host for ' $\mathrm{Ca}$. L. solanacearum' haplotypes $\mathrm{C}, \mathrm{D}$, or $\mathrm{E}$ or in an apiaceous plant infected with ' $\mathrm{Ca}$. L. solanacearum'.

After a high-quality genome sequence of the cultivated carrot (D. carota subsp. sativus) (Iorizzo et al. 2016) and a highquality draft genome sequence of ' $\mathrm{Ca}$. L. solanacearum' haplotype C (J. Wang et al. 2017) were obtained, a dual transcriptomic analysis of ' $\mathrm{Ca}$. L. solanacearum' haplotype $\mathrm{C}$ and its host plant carrot became possible. The aims of this study were i) to reveal the changes in carrot gene expression in connection with the development of disease symptoms in the infected plants and ii) to monitor the gene expression of ' $\mathrm{Ca}$. L. solanacearum' haplotype $\mathrm{C}$ within the host plant at different stages of the infection. To achieve these aims, carrot plants were exposed to short-time feeding by ' $C a$. L. solanacearum'harboring carrot psyllids or were left uninoculated, and samples were collected at 4, 5, and 9 weeks after inoculation for dual (plant and bacteria) transcriptome analysis using RNA-Seq.

\section{RESULTS AND DISCUSSION}

Infection of carrot seedlings with ' $\mathrm{Ca}$. L. solanacearum'.

'Ca. L. solanacearum'-free carrot seedlings were inoculated in two separate greenhouse experiments with ' $\mathrm{Ca}$. L. solanacearum' haplotype $\mathrm{C}$ carried by $T$. apicalis psyllids. Not all individual psyllids in the population harbor ' $C a$. L. solanacearum' in such a high relative titer that they could transmit the bacteria into the carrot plants in amounts leading to disease; therefore, to increase the chance of infection, two psyllids per plant were used in the inoculation experiments. To avoid excessive psyllid feeding damage in the seedlings, the psyllids were removed from the plants 3 days later. The relative titer of ' $\mathrm{Ca}$. L. solanacearum' in these psyllids was subsequently analyzed by real-time PCR. Although most of the psyllids used for inoculation harbored ' $\mathrm{Ca}$. L. solanacearum' in detectable amounts, less than half of them had a high enough titer, which is $>10^{3}$ (Nissinen et al. 2014), to properly infect the carrot seedlings (Supplementary Fig. S1). Unfortunately, a consistently ' $\mathrm{Ca}$. L. solanacearum'-negative $T$. apicalis colony that could have been used as a control in the inoculation experiments has not been obtained thus far. Although some psyllid individuals appeared ' $C a$. L. solanacearum'-negative in PCR tests, frequently such females produced ' $C a$. L. solanacearum'-positive progeny (A. Nissinen and M. Haapalainen, unpublished results). Similarly, the amount of ' $C a$. L. solanacearum' fluctuates in the potato psyllid B. cockerelli (Alvarado et al. 2012).

Three weeks after psyllid exposure, the third leaf of each seedling was collected to determine the ' $\mathrm{Ca}$. L. solanacearum' infection status by real-time PCR. In the first experiment, 11 of the 23 seedlings and, in the second experiment, 14 of the 21 seedlings exposed to the psyllids were infected with ' $\mathrm{Ca}$. L. solanacearum'. Because the third leaf had developed after the psyllids had been removed from the plants, the bacteria could only have reached this new leaf by first spreading down from the inoculated leaf to the root and then moving up into the developing leaf. This result indicates that, within 3 weeks from psyllid feeding, the infection was already systemic.

Samples for the RNA-Seq analysis were collected at 4 and 9 wpi in the first experiment and at 5 and 9 wpi in the second experiment. Three infected plants were chosen as samples at each timepoint, together with three noninoculated control plants. In the infected plant petioles, the relative titers of ' $\mathrm{Ca}$. L. solanacearum', calculated as the ratio of ' $\mathrm{Ca}$. L. solanacearum' $16 \mathrm{~S}$ ribosomal DNA to carrot ITS1 region, were $7.6 \times 10^{2}$ fold higher, on average, in the samples taken at 9 wpi than in the samples taken at 4 or 5 wpi, reflecting the growth of the bacterial population (Fig. 1A). In the first experiment, the relative ' $C a$. L. solanacearum' titers were significantly higher in the root than in the petioles at $4 \mathrm{wpi}$, whereas the difference between petioles and root tip was not significant at 9 wpi. In the second experiment the infected plants had significantly higher ' $\mathrm{Ca}$. L. solanacearum' titers in the petioles than in the root tip at both 5 and 9 wpi. The different distribution of the bacteria within the plants at 4 wpi in comparison with the later timepoints further suggests that the bacteria, spreading along the phloem stream, first colonized the root and from there spread to the new leaves.

\section{Phenotypic effects of ' $\mathrm{Ca}$. L. solanacearum' infection in carrot plants and tissues.}

At the time of inoculation, the carrot plants were small seedlings with two true leaves, while 9 weeks later, the plants had 
grown to have a fully developed foliage and a marketable size storage root. Exposure to carrot psyllid feeding and ' $\mathrm{Ca}$. L. solanacearum' infection reduced the carrot root weight and increased the foliage weight, resulting in lower root to foliage fresh weight ratio at 9 wpi in the infected carrots (Fig. 1B). The plants with a high ' $C a$. L. solanacearum' titer (relative titer $>10^{5}$ ) had a significantly lower root to foliage weight ratio than the other psyllid-exposed plants with low or no ' $\mathrm{Ca}$. L. solanacearum' infection (Fig. 1C), which supports our earlier results suggesting that the root weight reduction is related to a high titer of ' $\mathrm{Ca}$. $\mathrm{L}$. solanacearum' (Nissinen et al. 2014). At 9 wpi, the plants also displayed leaf discoloration symptoms. Although some leaf discoloration was also observed in the ' $\mathrm{Ca}$. L. solanacearum'-free control plants and the psyllid-exposed low or no ' $\mathrm{Ca}$. L. solanacearum' plants, probably due to plant aging, the ' $\mathrm{Ca}$. L. solanacearum' infection significantly increased discoloration in the highly infected plants (Fig. 1D).
When tissue samples of the infected carrot plants were taken at 9 wpi and were analyzed by transmission electron microscopy (TEM), ' $C a$. L. solanacearum' bacteria were observed inside the phloem sieve cells (Fig. 2A). The bacteria were not found in any other type of carrot cells. Plasmodesmata blocked with material, presumably callose, were observed in the wall between an infected sieve cell and the adjacent companion cell (Fig. 2B). The sieve cells densely populated with bacteria also seemed to contain dense, fibrous material, possibly P-protein aggregates (Fig. 2C and D). P-proteins have been suggested to seal damaged sieve tubes in Arabidopsis thaliana (Jekat et al. 2013). The number of phloem sieve cells appeared to be higher in the vascular tissues of the infected carrot leaves at 9 wpi (Fig. 2E) when compared with a healthy control plant (Fig. 2F). Carrots infected with ' $\mathrm{Ca}$. L. solanacearum' stay alive, although suffering from various symptoms, and thus, it is possible that the tolerance to ' $\mathrm{Ca}$. L. solanacearum' in carrots is related to phloem
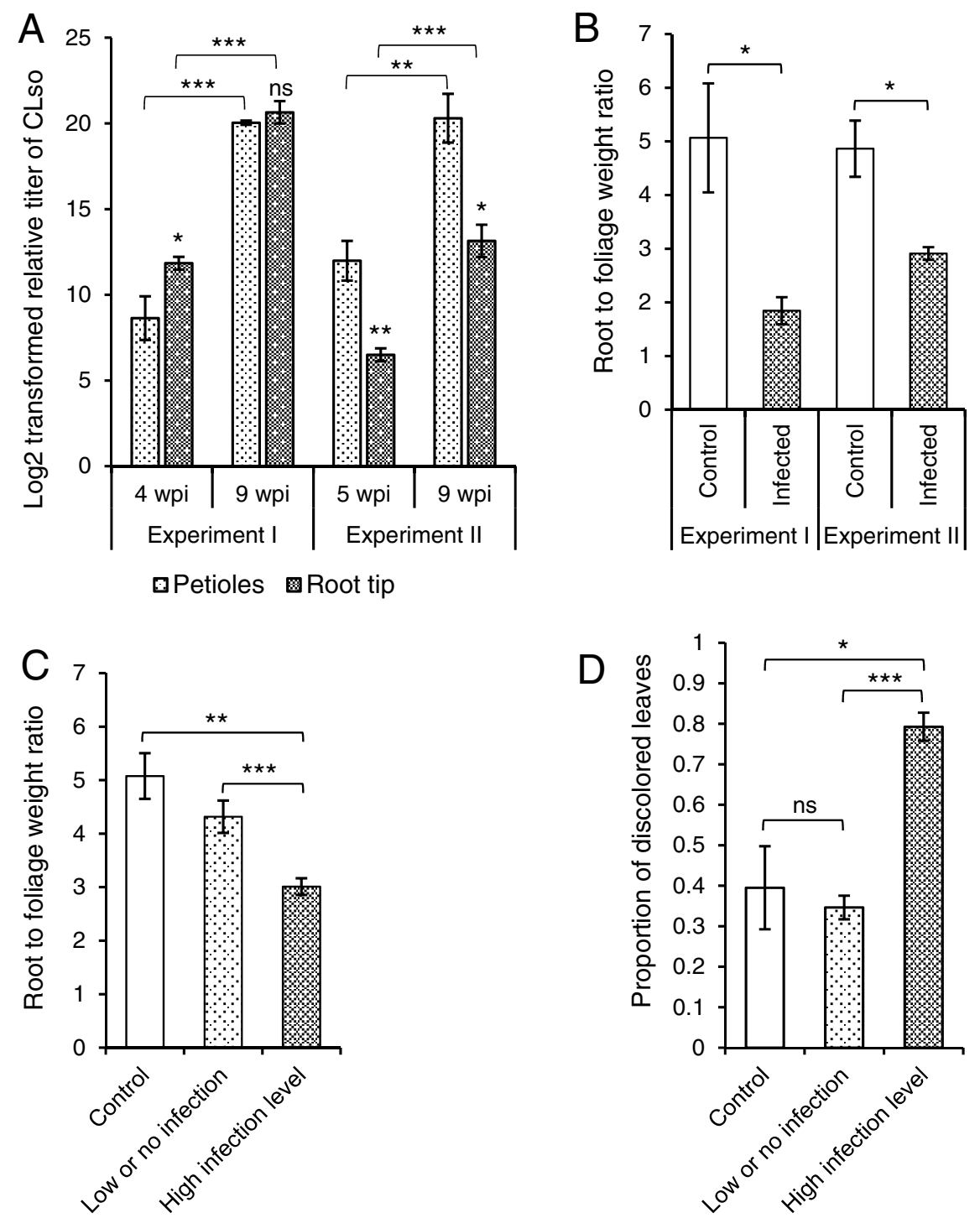

Fig. 1. Infection with 'Candidatus Liberibacter solanacearum' haplotype $\mathrm{C}$ and the associated symptoms in carrots. A, Log base 2-transformed relative titers of ' $C a$. L. solanacearum' in different parts of the infected carrots at different timepoints (wpi = weeks postinoculation) of the two experiments. B, Root to foliage weight ratio in the control and ' $\mathrm{Ca}$. L. solanacearum'-infected carrot plants sampled for RNA-Seq analysis at the 9-wpi timepoint in the two experiments. C, Root to foliage weight ratio, and D, proportion of discolored leaves in all the control and psyllid-exposed plants at the 9-wpi timepoint of experiment II. For the controls, $n=4$, for exposed plants with low or no ' $\mathrm{Ca}$. L. solanacearum' infection (relative ' $\mathrm{Ca}$. L. solanacearum' titer from 1 to $10^{2}$ ), $n=12$, and for highly infected plants (relative ' $\mathrm{Ca}$. L. solanacearum' titer $>10^{5}$ ), $n=6$. Markings above the connecting lines indicate a significant difference (one asterisk [*] indicates $P<0.05$, two $\left[{ }^{* *}\right] P<0.01$, three $\left[{ }^{* * *}\right] P<0.001$ ) or no significant difference (ns) by $t$ test. Markings on top of the root tip bars in A indicate significance of the difference between ' $\mathrm{Ca}$. L. solanacearum' titers in petioles and root tip within the same sample group. The error bars indicate \pm standard deviation $(A)$ or standard error of the mean $(B, C$, and $D)$. 
regeneration, which was recently identified as a tolerance mechanism in citrus fruit against ' $C a$. L. asiaticus' (Deng et al. 2019). In the ' $C a$. L. solanacearum'-infected leaves, the parenchyma cells surrounding the vascular bundles contained starch granules not observed in the healthy control (Fig. 2E and F). As a result of the impaired phloem transport, starch accumulation has been previously observed in the upper parts of the stems of potato plants infected with ' $C a$. L. solanacearum' (Alvarado et al. 2012) and in the leaves of citrus trees infected with ' $\mathrm{Ca}$. L. asiaticus' (Etxeberria et al. 2009; Granato et al. 2019).

\section{RNA-Seq datasets.}

Samples for the RNA-Seq analysis were prepared from leaf petioles, which have a relatively high proportion of vascular tissues, making them a good material for studying phloem-related disorders and ' $C a$. L. solanacearum' gene expression. RNA
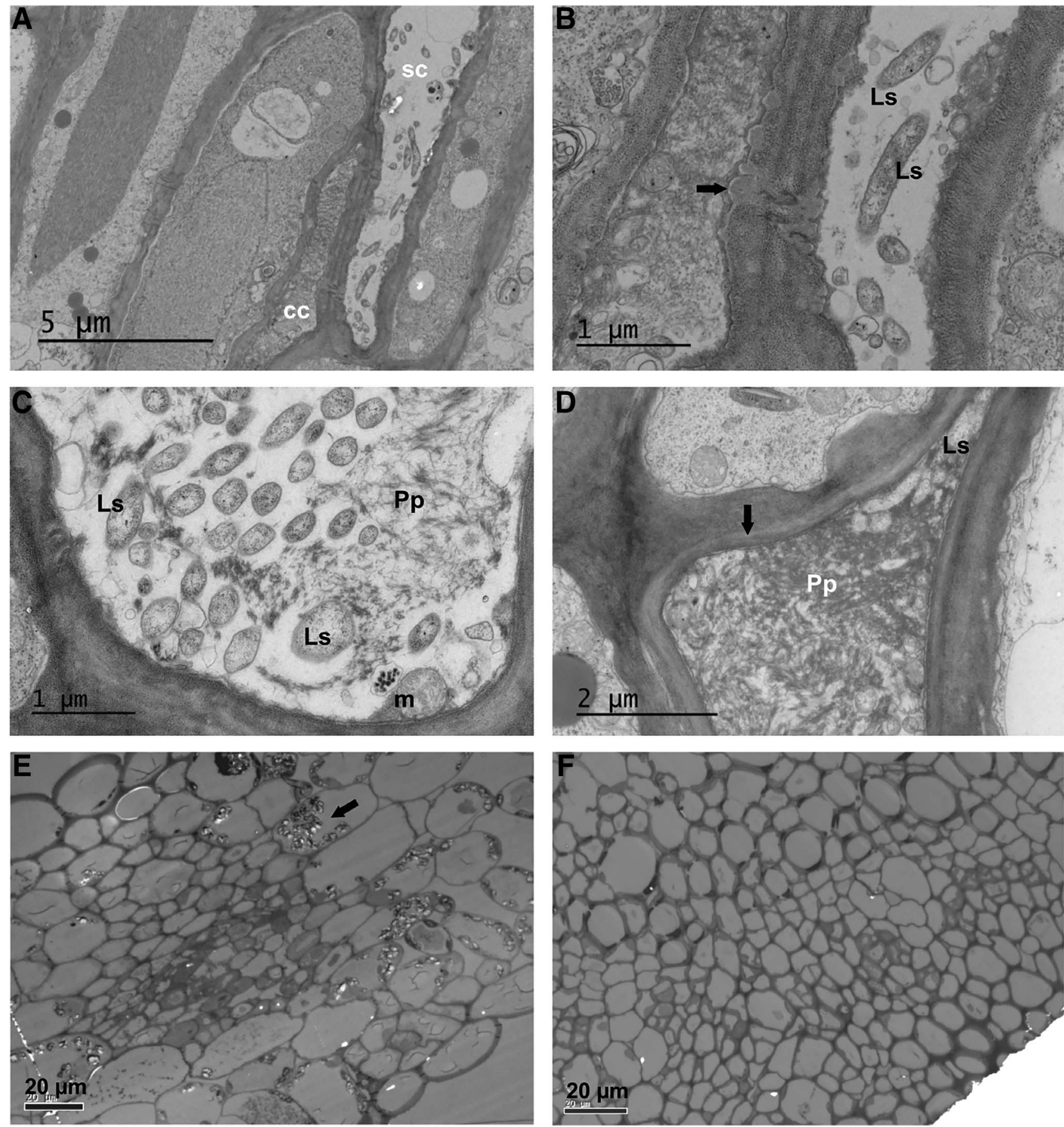

Fig. 2. Transmission electron micrographs of carrot phloem tissue infected with 'Candidatus Liberibacter solanacearum'. A, A sieve cell infected with ' $\mathrm{Ca}$. L. solanacearum' bacteria, a longitudinal section, 1,200x. B, Plasmodesmata in the longitudinal cell wall between the infected sieve cell and a companion cell blocked with callose (arrow), 5,000x, a close-up of A. C, Transection of a sieve cell containing ' $\mathrm{Ca}$. L. solanacearum' bacteria and P-protein aggregates, 5,000x. D, An additional layer of cell-wall material (arrow) deposited on the inside of the primary cell wall of a sieve cell filled with bacteria and P-protein aggregates, 3,000×. The micrographs shown in A, B, C and D are from the root collar zone. E, Multiple amounts of sieve cells in the leaf phloem (middle) and starch granules (arrow) in the surrounding parenchyma cells, 600x. F, For comparison, normal vascular tissues in a healthy carrot leaf, 800x. Abbreviations: $\mathrm{sc}=$ sieve cell, $\mathrm{cc}=$ companion cell, Ls $={ }^{\prime C} \mathrm{C}$. L . solanacearum’ bacteria, $\mathrm{m}=$ mitochondrion, $\mathrm{Pp}=\mathrm{P}$-protein . 
isolated from the carrot petiole samples was used for RNA-Seq experiments without polydT enrichment in order to obtain metatranscriptome samples. On average, there were 72.3 million reads per sample after adapter and quality trimming and length filtering (Supplementary Table S1). The majority of the ribosomal RNA (rRNA) was efficiently depleted by using RiboZero rRNA removal kits, and, on average, there were only 1,410 and 14 reads per sample mapping to the rRNA regions of carrot and ' $C a$. L. solanacearum', respectively. The cleaned datasets had an average of $86.58 \%$ overall mapping rate and approximately 62.60 million reads per sample aligned to the D. carota subsp. sativus (cultivar DH1) genome sequence (Supplementary Table S1). Of cleaned datasets, on average, 3.93 and $20.55 \%$ per sample mapped to the mitochondrial and chloroplast genomes of carrot, respectively, and $43.07 \%$ of total reads originated from protein-coding genes in the nuclear genome of carrot. Reads aligned to ' $C a$. L. solanacearum' haplotype $\mathrm{C}$ FIN114 genome sequence were only found in the inoculated plants. The sums of the reads mapped to the ' $\mathrm{Ca}$. L. solanacearum' genome at 9 wpi, 3.61 and 7.19 million in the first and the second experiment, respectively, were 108 and 26 times larger than at the early timepoints 4 and 5 wpi, respectively (Supplementary Table S1). Thus, the amounts of mapped RNA-Seq reads of ' $C a$. L. solanacearum' in the samples agreed well with the real-time PCR results on the ' $\mathrm{Ca}$. L. solanacearum' population (Fig. 1A). The principal component analyses (PCA) for the RNA-Seq datasets showed that the first principal component (PC1) and PC2 explain 44.12 and $14.64 \%$ of the total variation in experiment I and 30.03 and $20.14 \%$ in experiment II, suggesting that the infected samples and the control samples clustered into groups, which agrees with the experimental design (Supplementary Fig. S2). Hierarchical clustering of the RNA-Seq samples showed that, at each timepoint, the infected samples and control samples clustered into different groups, except for one sample, I-Ls3 (an infected 9-wpi sample from the first experiment) that clustered with the control samples (Supplementary Fig. S2). This sample was excluded from the differential expression analysis.

\section{Differentially expressed genes (DEGs) \\ in the ' $\mathrm{Ca}$. L. solanacearum'-infected carrot plants.}

In the first experiment, 880 and 3,369 DEGs of carrot nuclear genes were identified by comparison between the infected and control plants at the two postinoculation timepoints, 4 and 9 wpi, respectively. In the second experiment, 1,640 and 5,231 DEGs of carrot at 5 and 9 wpi, respectively, were identified by comparison between the infected and control plants (Supplementary Table S2; Supplementary Fig. S3). Of these DEGs, 261 were common to both of the early timepoints, and these shared DEGs constituted $29 \%$ of the 4-wpi DEGs and about $16 \%$ of the 5-wpi DEGs. Of the late timepoint (9 wpi) DEGs, 1,647 were common to both of the experiments, and these shared DEGs constituted 49 and $31 \%$ of the 9-wpi DEGs in the first and the second experiment, respectively.

In all, 99 DEGs of carrot were found in the four sample sets, which suggests that the expression of these genes was affected by the 'Ca. L. solanacearum' infection at both the early and late stages. The most strongly upregulated genes encoded kiwellinlike protein, sugar transport protein 13 , two acidic endochitinaselike proteins, and probable disease resistance protein At5g66910, and the most strongly downregulated genes included deacetylvindoline $O$-acetyltransferase, NADP-dependent D-sorbitol-6-phosphate dehydrogenase, transcription factor HY5 (ELONGATED HYPOCOTYL5), F-box protein At5g49610 homolog, and cactin (Supplementary Table S3). Ten chloroplast genes, most of them coding for components of the cytochrome b6f complex, appeared differentially expressed in the infected plants at all the timepoints, eight genes down- and two upregulated (Supplementary Table S4).

Enrichment analyses of gene ontology (GO) terms and Kyoto Encyclopedia of Genes and Genomes (KEGG) pathways were performed to explore the carrot transcriptomic responses to psyllid feeding and ' $\mathrm{Ca}$. L. solanacearum' infection (Supplementary Table S5). The results showed that the most frequently upregulated GO terms and KEGG pathways were involved in protein synthesis and secretion, phenylpropanoids, lipid biosynthesis, and proteasome, whereas hormonal regulation and plant-pathogen interaction were evident only in some samples. Downregulated GO terms and KEGG pathways were related to transcription, replication, secondary metabolites, photosynthesis, and internal cellular compartments such as cytosol, cytoskeleton, and nucleoplasm. More drastic changes were seen in the 5- and 9-wpi samples, probably due to the higher relative titer of ' $C a$. L. solanacearum' in those plants. The GO and KEGG results were manually checked and the functions of the representative genes that were observed in several enriched datasets or timepoints were found by searching the databases and literature to reveal their possible connection to the observed phenotypic changes.

\section{Transcriptome data suggests}

increased protein synthesis in the infected plants.

At all the timepoints, GO terms identified enriched functions 'translation', 'ribosome', or 'RNA binding', which indicates that the expression of a large number of ribosomal proteins was induced (Supplementary Table S5). This suggests that the carrot plants responded to the psyllid feeding and ' $\mathrm{Ca}$. L. solanacearum' infection with increased protein synthesis. In the 5- and 9-wpi samples, GO terms 'endoplasmic reticulum', 'protein processing in ER', and KEGG pathway 'N-glycan biosynthesis' also suggested induced protein modification and transport. Furthermore, the KEGG pathway 'amino acid related enzymes' contained numerous amino acid-transfer RNA ligase genes, most of them upregulated, to support the translation of new proteins (Supplementary Table S5). In 9-wpi datasets, KEGG pathways 'glycine, serine and threonine metabolism' and 'alanine, aspartate and glutamate metabolism' showed both up- and downregulated genes in the first experiment, whereas most genes were up-regulated in the second experiment (Supplementary Tables S2 and S5). In previous studies an increase in free amino acids, especially asparagine and glutamine, was observed in carrot leaves damaged by carrot psyllid feeding (Laurema 1989). Alanine, proline, and glutamine were predominant amino acids in the psyllids (Laurema 1989), which may suggest that carrot psyllids are capable of enhancing the development of their offspring by regulating the plant amino acid metabolism. The enzyme glutamate decarboxylase (GAD1) was up-regulated especially in the 9-wpi samples. This enzyme synthesizes a nonprotein amino acid gamma-aminobutyric acid (GABA), a component of the GABA shunt that bypasses two steps of the tricarboxylic acid (TCA) cycle and integrates amino acid metabolism with carbohydrate metabolism. GABA also has a signaling function, for example, in resistance to stress and pathogens, in nutrient recycling, and cell-wall biosynthesis (Michaeli and Fromm 2015).

One of the major findings of enrichment analyses was that many enriched GO terms and KEGG pathways observed at all timepoints covered downregulated basic cellular functions and cell compartments. In 4-wpi samples, the genes in GO terms 'nucleoplasm', 'nuclease activity', and 'cytosol' and KEGG pathways 'transcription machinery' and 'spliceosome' were downregulated. In the 5- and 9-wpi samples, GO terms 'endosome', 'cytoskeleton', 'cell cycle', 'signal transduction', 'DNA metabolic process', and 'RNA binding' also were down-regulated. Similarly, KEGG pathways 'transcription machinery', 'basal transcription 
factors', 'RNA polymerase', 'RNA transport', 'mRNA surveillance', 'homologous recombination', 'DNA replication', 'DNA metabolic process', 'base-excision repair', 'RNARE interactions in vesicular transport', 'endocytosis', 'phagosome', and 'cytoskeleton proteins' were suppressed in many of the infected plants. These results suggest that the plants downregulate transcription, DNA replication, and endocytosis to combat the infection.

\section{Phloem and cell wall-related gene expression in the infected plants.}

Because the infected phloem cells appeared to contain callose depositions and P-protein aggregates, gene expression changes related to these phenomena were looked for in the RNA-Seq data. In both of the 9-wpi sample sets, increased expression of genes coding for phloem occlusion proteins and phloem protein 2 (PP2)-like proteins were observed, and, in the second experiment, callose synthase 7 genes also were up-regulated. In citrus infected with ' $\mathrm{Ca}$. L. asiaticus', callose depositions blocking the plasmodesmatal transport were observed in the leaf phloem (Koh et al. 2012) and upregulation of callose synthase 7 was associated with the callose deposition at the phloem sieve pores (Granato et al. 2019). CALLOSE SYNTHASE 7 has been shown to be responsible for callose formation in the phloem tissues in A. thaliana (Xie et al. 2011). Phloem occlusion proteins are homologous to P-proteins and SIEVE ELEMENT OCCLUSION B-like (SEO) proteins, suggested to seal the damaged sieve tubes in A. thaliana (Jekat et al. 2013), and PP2 has been suggested to participate in phloem blockage in ' $C a$. L. asiaticus'-infected Citrus sinensis (Aritua et al. 2013).

Obstructions in phloem transport may affect the transport of photosynthates and signaling molecules from shoot to root. Sucrose and other hexoses, peptides, proteins, amino acids and their derivatives, phytohormones, secondary metabolites, and mRNAs have all been suggested as phloem mobile signals that modulate growth and defense against pathogens (van Bel et al. 2013; Wheeldon and Bennett 2021). One of the genes downregulated in all the infected plants was HY5, which has been identified as a phloem-transported shoot-to-root signal in A. thaliana (Chen et al. 2016). HY5 promotes the sugar transport from shoot to root, thus enhancing the root growth and reducing the shoot growth (Wheeldon and Bennett 2021). Thus, the reduced expression of HY5 in all the infected carrot plants in this study may, together with the reduced phloem transport of the HY5 protein, other signaling molecules and the photosynthates, contribute to the observed root growth reduction in the infected plants. As HY5 was already downregulated at the early timepoints, it is possible that the modified resource allocation was first induced by the psyllid feeding.

The expression levels of many sugar transporters were altered in the infected plants. The expression of SWEET-like sugar efflux transporters, found to release sugars to the apoplast during interaction with compatible pathogens (Chen et al. 2010), was down-regulated, whereas the sugar transporter 13 (STP13), transporting hexoses from the apoplast to the cytoplasm (Yamada et al. 2016), was up-regulated at all timepoints. Upregulation of STP13 has been previously shown to promote resistance to Botrytis cinerea and Pseudomonas syringae, due to the increased transport of hexoses away from the apoplast, leading to less optimal conditions for the growth of these extracellular pathogens (Lemonnier 2014; Yamada et al. 2016). However, in the case of ' $\mathrm{Ca}$. L. solanacearum' infection, the result could be the opposite, as the upregulation of STP13, assumingly leading to enhanced transport of sugar from the apoplast into the cells, may support the growth of the intracellular pathogen.

In the 4- and 5-wpi samples and in the 9-wpi dataset of the first experiment, GO term 'cell wall' contained upregulated genes encoding expansins, polygalacturonases, pectinesterases, and xyloglucan-modifying enzymes, suggested to be involved in cell-wall expansion and remodeling (Chebli and Geitmann 2017; Marowa et al. 2016; Rui et al. 2017). Many of these genes were also included in the partially overlapping GO term "extracellular region' that was enriched with upregulated genes in the 5- and 9-wpi datasets. Expression of these genes may be involved in forming new phloem cells to replace the blocked ones. Furthermore, the genes in the KEGG pathway 'phenylpropanoid biosynthesis', including most of the genes in the monolignol biosynthesis module, were up-regulated in the 5- and 9-wpi samples, suggesting that building blocks of lignin were formed. Lignin is abundant in the secondary cell walls in the vascular bundles of stems and leaves (Yoon et al. 2015). An additional layer of cell-wall material was observed on the inside of the primary wall of the heavily infected carrot sieve cells (Fig. 2D), probably isolating the dysfunctional cells and the bacteria from the other phloem cells. Based on the changes in gene expression, the deposited material could be lignin. Presence of lignin and lignin-derived compounds has also been previously detected in the phloem of sugar beets infected with the phloem-limited pathogen 'Candidatus Phlomobacter fragariae' (Gatineau et al. 2002).

\section{Transcriptional changes of secondary metabolite biosynthesis genes.}

Large numbers of genes in the phenylpropanoid biosynthesis pathway were differentially expressed (Supplementary Table S2). In addition to monolignols, the KEGG pathway 'phenylpropanoid biosynthesis' is involved in the biosynthesis of hydroxycinnamic acids, such as caffeic, ferulic, and sinapic acids. Hydroxycinnamic acids are toxic to bacteria, fungi, and insects and are found in the carrot cell walls (Parr et al. 1997), and elevated concentrations of ferulic acid and vanillic acid have been observed in the roots of carrot plants damaged by psyllid-feeding (Nissinen et al. 2012). Many genes involved in production of terpenes were identified among the enriched genes or DEGs (Supplementary Table S2). For example, genes annotated as terpene synthase 10-like and alpha-farnesene synthase-like were up-regulated at 4 wpi. These genes are linked to the production of terpenoids that act as insect repellents, attractants, or toxins (Pichersky and Raguso 2018). Thus, the upregulation of terpenoid biosynthesis genes at 4 wpi could have been induced by the psyllid feeding and possibly lead to increased production of volatile terpenoids. However, at the 9-wpi timepoint of the first experiment, 'terpenoid backbone biosynthesis' was identified as a suppressed KEGG pathway, including genes annotated as sesquiterpenoid germacrene $\mathrm{D}$ and monoterpenoid limonene synthases. Similar downregulation of terpenoid volatile production has been shown in citrus roots infected with ' $C a$. L. asiaticus' (Zhong et al. 2015). Psyllidfeeding was previously shown to induce changes in the volatile monoterpenoids of carrot leaves (Nissinen et al. 2005), psyllidfeeding and ' $\mathrm{Ca}$. L. solanacearum' induced terpenoids in solanaceous plants, and ' $\mathrm{Ca}$. L. asiaticus' infection in citrus (Hijaz et al. 2016; Mas et al. 2014; Wallis et al. 2015). In addition, other terpenoid pathways were down-regulated, such as zeatin biosynthesis at 5 wpi and the carotenoid biosynthesis pathway, especially the abscisic acid (ABA) module at 9 wpi, in the first experiment (Supplementary Table S5). KEGG pathway 'flavonoid biosynthesis' was down-regulated at both timepoints of the first experiment and genes with similar annotations were also downregulated in the second experiment. Changes in the biosynthesis of phenylpropanoids and other secondary metabolites in the infected carrots may be linked to defense against psyllids or bacteria. Since the psyllids were removed from the plants already after 3 days of feeding, it is likely that the bacterial infection rather than the psyllid feeding affected carrot gene expression at the late timepoint. 


\section{Changes in lipid metabolism in the infected plants.}

One of the most drastic responses in the infected plants was the change in the lipid biosynthesis (Supplementary Table S5). GO class 'lipid metabolic process' and KEGG pathways 'fatty acid biosynthesis', 'biosynthesis of unsaturated fatty acids', 'lipid biosynthesis proteins', 'lipid metabolic proteins', and, in the second experiment, 'alpha-linolenic acid metabolism' were all upregulated. At 5 and 9 wpi, the upregulated genes included stearoyl-(acyl-carrier-protein) 9-desaturase FAB2-like gene and a large cluster of genes encoding $\Delta(12)$-fatty-acid desaturase FAD2-like proteins. FAD2 enzymes may be involved in converting oleic acid to linoleic acid, a precursor of jasmonic acid (JA), whereas some atypical FAD2 proteins may be involved in the biosynthesis of the polyacetylenes falcarindiol and falcarinol (Busta et al. 2018). These secondary metabolites are toxic to bacterial cells and are produced by carrot as a response to carrot psyllid feeding (Hinds et al. 2017; Seljåsen et al. 2013), suggesting an upregulated defense against psyllids and bacteria. Various lipids and unsaturated fatty acids, possibly functioning as membrane components or signaling molecules, can also mediate induced stress tolerance (Okazaki and Saito 2014). The downregulation of KEGG pathway 'glycerolipid metabolism' at 9 wpi suggests reduced biosynthesis of triacylglycerols, which may be a consequence of the changes in resource allocation. It seems that, in the infected carrot plants, remodeling of fatty acid metabolism takes place, possibly to maintain the membrane lipid homeostasis and to provide alpha-linolenic acid for JA production.

\section{Transcriptional changes of carrot genes involved in plant immunity.}

Partially overlapping KEGG pathways 'MAPK signaling' and 'plant-pathogen interaction' were observed at 9 wpi in the first experiment and at 5 wpi in the second experiment (Fig. 3; Supplementary Table S5). Approximately one-fourth of the genes included in the KEGG pathway related to 'MAPK signaling' were up-regulated at 5 wpi. This pathway includes genes like BRASSINOSTEROID INSENSITIVE 1 (BAK1), flagellin receptor FLS2, ABA receptor PYL4-like, mitogen-activated protein kinase kinase 2-like, defense regulator protein $\mathrm{MKS1}$, and PR protein PR-1. Thus, the activation of this pathway in the infected plants indicates that the plants had recognized the bacteria before the 5-wpi timepoint and responded with induced defense responses. In the 9-wpi data of the second experiment, KEGG pathway 'plant pathogen interaction' was identified, including, among others, LysM domain receptor-like kinase 3, BRASSINOSTEROID INSENSITIVE 1-associated receptor kinase 1 (BAK1)-like, leucine-rich repeat (LRR) receptor-like serine/threonine-protein kinase FLS2, RPM1-interacting protein 4-like (RIN4-like), ENHANCED DISEASE SUSCEPTIBILITY 1-like (EDS1-like) genes and several genes coding for calcium signaling. The upregulation of FLS2, LysM-domain receptors, and BAK1-like genes suggest that the pathogen-associated molecular pattern-triggered immunity (PTI) was activated in the infected plants.
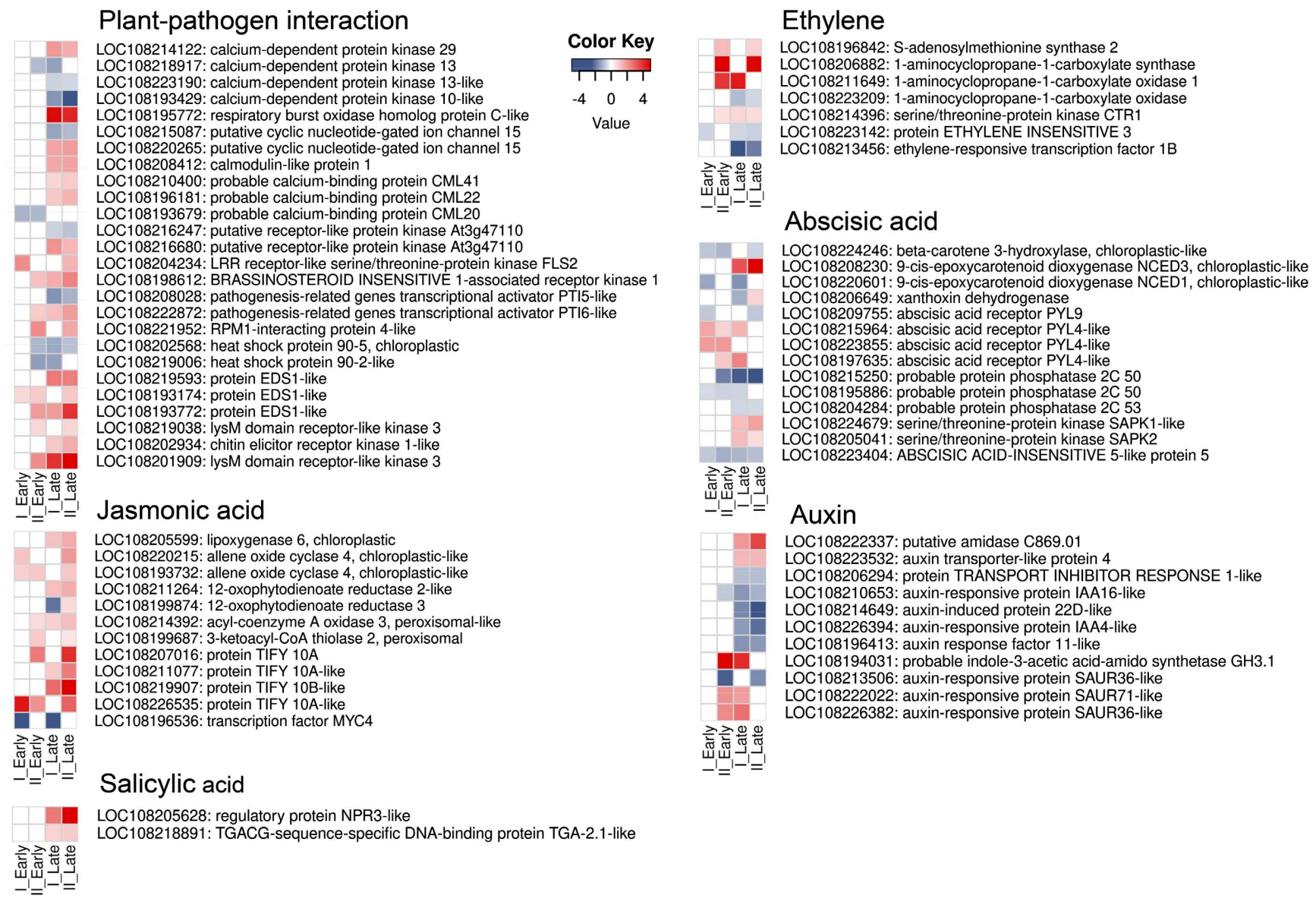

Fig. 3. Changes in the phytohormone and defense gene expression in the petioles of carrot plants infected with 'Candidatus Liberibacter solanacearum'. Heat maps of relative gene expression levels ( $\log _{2}$ fold change) for genes annotated in the Kyoto Encyclopedia of Genes and Genomes pathways 'plantpathogen interaction', 'plant hormone signal transduction', and in the phytohormone biosynthesis modules. The red, blue, and white in the heat map indicate upregulation, downregulation, and no change, respectively, in relation to the control plants. Each row represents a gene and each column represents the result of the comparison between the infected and control plants in the sample (experiment I or II and timepoint early or late). Only genes present in at least two datasets are shown. 
Increased expression of genes annotated to code for nucleotide-binding LRR (NLR) resistance proteins could be identified in the 5- and 9-wpi data, 13 NLRs at 5 wpi, and 36 at 9 wpi (Supplementary Table S2). Plants utilize NLRs to recognize pathogen effectors, which leads to effector-triggered immunity (ETI). Especially, several genes coding for toll-like/ interleukin 1 receptor (TIR)-type tobacco mosaic virus resistance protein $\mathrm{N}$-like proteins were induced. In addition, induced nonTIR proteins were evident in the data, and among these proteins were RPW8-NLR-like probable disease resistance protein At5g66910, which was up-regulated at all the timepoints (Supplementary Table S2). In A. thaliana, At5g66910 is called N REQUIREMENT GENE 1 (NRG1). Diverse NLR immune receptors activate the defense response via NRG1 and its homologs in the ACTIVATED DEFENSE RESISTANCE 1 (ADR1) gene family in A. thaliana (Castel et al. 2019; Dong et al. 2016). A member of the ADR1 gene family, annotated as probable disease resistance protein At4g33300 (LOC108228075), was up-regulated at 4 wpi in the first experiment and at 5 and 9 wpi in the second experiment. A coevolved module composed of EDS1, NRG1, and SENESCENCE-ACTIVATED 101 (SAG101) has been shown necessary for the cell-death response mediated by TIR-domain immune receptors in A. thaliana (Lapin et al. 2019). EDS1 and SAG101 are lipase-like proteins and work in Arabidopsis in complexes with a third lipase-like protein, PAD4. Homologs of both SAG101 and PAD4 were among the upregulated carrot genes, suggesting that an ETI-like response could have been induced in the infected carrot plants.

Many genes encoding pathogenesis-related (PR) proteins, especially PR-1, PR-2, and PR-5, and chitinases, $\beta-1,3$-glucanases, defensins, thaumatin-like proteins, hevamins, and proteins annotated as allergens were up-regulated at both the early and late timepoints in both experiments. Some of these genes were in the GO class 'response to biotic stimulus', further suggesting induced plant defenses against ' $C a$. L. solanacearum' infection. The DEGs that were up-regulated in all the infected plants included kiwellin-like protein and acidic endochitinase-like proteins (Supplementary Table S3). A maize kiwellin (ZmKWL1) can inhibit the metabolic activity of the secreted fungal effector chorismate mutase 1 (Han et al. 2019), and, in many plant species, chitinases are induced in response to pathogen attack and contribute to the plant resistance (Grover 2012). Furthermore, hevamine-A, upregulated at 5 wpi and both of the 9-wpi timepoints, is similar to $A$. thaliana LYS1, which has lysozyme-like activity that releases defense-inducing peptidoglycan fragments from the bacterial cell wall (Liu et al. 2014).

\section{Altered expression levels of genes involved in plant hormonal regulation.}

GO class 'response to endogenous stimulus' in both of the 9-wpi datasets and KEGG pathway 'plant hormone signal transduction' in the first 9-wpi dataset contained genes involved in the production of plant hormones (Supplementary Table S5). Signaling pathways of several plant hormones are regulated by protein degradation by proteasome, which most likely results in the induction of the KEGG pathways 'proteasome' and 'ubiquitin mediated proteolysis' observed at 5 and 9 wpi. Due to the central role of plant hormones in plant defense and response to pathogens, the expression patterns and functions of the genes related to hormonal signaling were carefully analyzed.

Biosynthesis of JA seemed enhanced in the ' $\mathrm{Ca}$. $\mathrm{L}$. solanacearum'-infected plants, especially at 5 and 9 wpi (Fig. 3). KEGG pathway 'alpha-linolenic acid metabolism', containing all the genes in the JA biosynthesis module, was up-regulated at 9 wpi in the second experiment and many of the genes were also upregulated in the other datasets (Fig. 3; Supplementary Table S5). However, four genes encoding the jasmonate ZIM-domain protein (JAZ) family proteins, repressors of the jasmonate signaling, were also upregulated in the infected plants, while one or more of the MYC4, MYC2-like, and MYC3-like transcription factors were down-regulated at all the timepoints, suggesting that the upregulated JA biosynthesis did not necessarily lead to activated JA signaling. The lipase-like proteins EDS1 and PAD4 have been previously suggested to antagonize JA signaling to promote SA defense during ETI induced by $P$. syringae (Cui et al. 2018). Thus, the upregulation of JAZ, EDS1, and PAD4 in carrots could be a response to ' $\mathrm{Ca}$. L. solanacearum' infection.

Expression levels of genes involved in the two pathways of salicylic acid (SA) biosynthesis were not altered, except for the genes encoding SA receptor NPR3-like and transcription factor TGA2.1 that were up-regulated in the infected plants at 9 wpi. In tobacco, TGA2.1 was shown to interact with NPR1 (Thurow et al. 2005), whereas NPR3 functions as a transcriptional repressor by binding to the TGA transcription factors to downregulate the defense-related genes in the absence of SA, and thus plays a role opposite to NPR1 (Ding et al. 2018). However, in A. thaliana, NPR3 has been suggested to be involved in upregulating JA biosynthesis during ETI induced by biotrophs, to prevent downregulation of defense against necrotrophic pathogens due to the SA-JA antagonism (Liu et al. 2016). In the citrus plants exposed simultaneously to psyllids and ' $\mathrm{Ca}$. L. asiaticus', JA biosynthesis was down-regulated and SA biosynthesis was up-regulated in comparison with the plants only exposed to the psyllid feeding (Nehela et al. 2018), which suggests that SA biosynthesis and signaling plays a role in the interaction between citrus plants and ' $\mathrm{Ca}$. L. asiaticus'. In tomato and potato plants, both SA and JA pathways have been suggested to be affected by 'Ca. L. solanacearum' (Casteel et al. 2012; Levy et al. 2017). Previously, other herbivore-associated bacteria have been suggested to suppress plant defenses in advantage of their arthropod hosts, such as Colorado beetles, whiteflies, spider mites, thrips, and wheat aphids (Chung et al. 2013; Li et al. 2019; Schausberger 2018; Su et al. 2015). Thus, it is possible that 'Ca. L. solanacearum' could also have an effect on the feeding of T. apicalis on carrot.

Ethylene is required for stress responses and triggers adaptive responses leading to tolerance to microorganisms, while it also affects plant growth (Dubois et al. 2018; Ravanbakhsh et al. 2018). Ethylene is also involved in the plant responses to herbivory, in which two alternative signaling pathways, JA-dependent and ethylene-dependent pathways, have been presented (Paudel and Bede 2015). In this study, genes encoding 1-aminocyclopropane-1-carboxylate synthase and 1-aminocyclopropane-1-carboxylate oxidase, catalyzing ethylene biosynthesis, were up-regulated in the infected plants. However, a homolog of serine/threonineprotein kinase CTR1, a negative regulator of ethylene, also was induced, whereas ethylene insensitive 3 (EIN3) and ethylene-responsive transcription factor 1B (ERF1B) were downregulated in both 9-wpi datasets (Fig. 3). On the whole, it seems that the ethylene-related signal transduction was suppressed in the infected plants.

ABA biosynthesis seemed downregulated in the infected plants (Fig. 3). Expression of the positive transcription factor ABA-insensitive 5-like 5 (AREB1/ABF2) was down-regulated at all the timepoints in the infected plants, while the PP2C enzymes, the negative regulators of ABA signaling, were also all down-regulated. Some of the ABA-related genes are induced by JA, among them ABA receptor PYL4 of A. thaliana and tobacco (Lackman et al. 2011) or induced by pathogens, such as the biosynthesis gene NCED3 of A. thaliana (Fan et al. 2009). It is possible that the upregulated expression of the homologous carrot genes in the infected plants was related to increased JA production. 
Several genes involved in auxin and indole 3-acetic acid (Aux/IAA) biosynthesis and signaling were differentially expressed, and, at 9 wpi, these genes were mostly downregulated (Fig. 3; Supplementary Table S2). However, some genes were up-regulated, including an Aux transporter-like protein 4, two SAUR-like proteins, and probable IAA-amido synthetase GH3.1. The effects of these transcriptional changes on the Aux-mediated signaling are difficult to predict, because the effects depend on the combinations of Aux/IAA and the Auxresponse factors (ARFs), and the different ARFs can be either transcriptional activators or repressors. Of the DEGs encoding gibberellin (GA) biosynthesis enzymes, GA 20 oxidase 2 (GA20OX2) was up-regulated at 5 wpi and in both 9-wpi datasets, GA 3-beta-dioxygenase 1 (GA3OX1), converting GA precursors into the bioactive forms, was up-regulated at 4 and 5 wpi, and the GID1C-like GA receptor gene was up-regulated at both timepoints in the second experiment. Furthermore, the expression of the DELLA protein GAI1, a negative regulator of GA signaling, was down-regulated at both timepoints in the second experiment. Also, however, a gene encoding GA 2-beta-dioxygenase (GA2OX) family protein, involved in GA deactivation, was up-regulated at 5 wpi and both the 9-wpi timepoints (Supplementary Table S2). Very few cytokinin-related genes were differentially expressed in the infected carrots. Most of those that were statistically significant were encoding zeatin $O$-glucosyltransferase-like proteins, which are involved in generating the glycosylated, stored forms of zeatin (Supplementary Table S2).

Altogether, the gene expression data suggested that increased biosynthesis of JA was the main hormonal change in the infected carrot plants. JA has been shown to protect plants against insects and pathogens, but it also antagonizes root growth (Major et al. 2017). Thus, it is possible that the decrease in root to foliage weight ratio observed in the infected carrot plants is, at least partially, resulting from the effect of JA on the other phytohormones and growth. Along with ABA and ethylene, JA also promotes chlorophyll degradation and chlorosis (Zhu et al. 2017). Yellowing is one of the main symptoms of ' $\mathrm{Ca}$. L. solanacearum' infection in carrot leaves, and it could be related to the increased production of JA, which affects the ratio between chlorophyll, anthocyanins, and carotenoids.

\section{Reduced photosynthesis and chloroplast functions in the infected plants.}

One of the most distinct effects of the ' $\mathrm{Ca}$. L. solanacearum' infection observed in the GO and KEGG analyses was the differential expression of genes related to chloroplast and photosynthesis (Supplementary Table S5). At 4 wpi, the genes in GO terms 'chloroplast' and 'thylakoid' and in KEGG pathways 'photosynthesis' and 'photosynthesis proteins', were up-regulated, whereas at the later timepoints, the genes included in those GO terms and KEGG pathways were down-regulated. The downregulation of photosynthesis is most likely linked to the tradeoff between defense and growth, which both SA and JA signaling have been suggested to regulate (Major et al. 2017; van Butselaar and Van den Ackerveken 2020). The reason why photosynthesis is down-regulated during the defense response might be the reallocation of nitrogen resources to produce PR proteins and resistance proteins to protect the plant tissues against the pathogen (Huot et al. 2014). Chloroplasts are also the source of many compounds needed for defense and defense-related signaling, like SA and reactive oxygen species (ROS) and the precursors of JA, and thus the production of these compounds may be prioritized over photosynthesis during the infection.

In contrast to the photosynthesis-related functions, many genes included in the GO term 'mitochondrion' were up-regulated at 5 and 9 wpi. Genes in the KEGG pathway 'glycolysis/gluconeogenesis' were up-regulated at both timepoints of the second experiment and 'pyruvate metabolism' and 'citrate cycle (TCA cycle)' at 5 wpi. Slight upregulation of genes encoding proteins in the TCA cycle, especially malate dehydrogenases, was also evident at 9 wpi. Downregulation of photosynthesis and upregulation of oxidative processes observed at the 5- and 9-wpi timepoints suggest that progressing ' $C a$. L. solanacearum' infection induced defense responses, for which the energy was derived from stored resources instead of photosynthesis. This conclusion is supported by the upregulation of many genes in the GO class 'catabolic process' at both timepoints of the second experiment.

Many of the gene expression changes observed in the ' $\mathrm{Ca}$. L. solanacearum'-infected carrots-enhanced protein synthesis and defense against pathogens, downregulation of photosynthesis, and changes in the synthesis of phenylpropanoids, secondary metabolites and phytohormones - have been observed in potato plants infected with ' $C a$. L. solanacearum' and citrus plants infected with ' $\mathrm{Ca}$. L. asiaticus', suggesting common patterns in the interaction of these two $\mathrm{Ca}$. Liberibacter species with their host plants (Hu et al. 2017; Huot et al. 2018; Levy et al. 2017; Nehela et al. 2018). Furthermore, downregulation of photosynthesis has been characterized as a global adaptive response of plants to biotic stresses caused by pathogens and herbivores, and this response can be triggered by developmental reprogramming, hormone crosstalk, or pathogen effectors (Bilgin et al. 2010; Huot et al. 2014; Sowden et al. 2018). In addition to the photosynthesis functions, especially photosystem II, several photosynthesis-related pathways, such as flavonoids, photorespiration, and ROS scavenging enzymes also were shown to be downregulated as a general response to pathogens and herbivores (Bilgin et al. 2010). All these pathways were also found to be downregulated in the ' $C a$. L. solanacearum'-infected carrots in this study.

\section{'Ca. L. solanacearum' gene expression in the infected carrot phloem.}

Based on the RNA-Seq data of the three 5-wpi samples and six 9-wpi samples, 997 protein-coding genes of ' $\mathrm{Ca}$. L. solanacearum' were defined as genes expressed in planta (Supplementary Table S6). Many of the highly expressed genes encode proteins related to the basic bacterial cell cycle, such as ribosomal proteins, membrane proteins, and chaperons. Also, the gene AYJ09_RS03495 that encodes superoxide dismutase, required for protection against ROS, and the genes responding to external stimuli, including genes encoding heat-shock and cold-shock proteins and transcriptional regulators, were expressed at high levels. The gene encoding Flp family type IVb pilin and several genes encoding hypothetical proteins also had high expression levels. Two of these hypothetical proteins (AYJ09_RS01100, AYJ09_RS04895) were haplotype C-specific and one (AYJ09_RS04095) has a homolog in ' $\mathrm{Ca}$. L. solanacearum' haplotype $\mathrm{D}$, which suggests that these proteins may contribute to the survival of ' $C a$. L. solanacearum' in the host plant carrot. The protein encoded by AYJ09_RS04095 has $\beta$-sheet structures and shows homology to bacterial porins, suggesting it could be an outer membrane protein. It was previously identified as one of the secreted proteins (J. Wang et al. 2017). Two more putative secreted proteins were among the expressed ones, AYJ09_RS01100, which was constantly expressed and ranked within the top 30 in all samples, and AYJ09_RS0074, which was expressed and ranked between 200 and 500. The gene AYJ09_RS04970, encoding a monooxygenase homologous to the salicylate hydroxylase previously identified in 'Ca. L. asiaticus' ( $\mathrm{Li}$ et al. 2017), was expressed at all timepoints (Supplementary Table S6). Thus, ' $\mathrm{Ca}$. L. solanacearum' haplotype $\mathrm{C}$ may also produce salicylate hydroxylase to counteract the plant defense signaling. Flagellar genes of ' $\mathrm{Ca}$. L. solanacearum' were expressed in all the samples, however, FlbT (AYJ09_RS03395), a posttranscriptional repressor of the flagellum biogenesis, was 
expressed at a high level, which suggests that ' $\mathrm{Ca}$. L. solanacearum' may not produce flagella in planta.

The genes within the two prophage regions $\mathrm{A}$ and $\mathrm{B}$ in the chromosome of ' $\mathrm{Ca}$. L. solanacearum' haplotype $\mathrm{C}$ showed lower expression levels than the genes in the bacterial core genome, in agreement with the prophage latency. Four of the phage-related genes had moderate expression levels, two genes (AYJ09_RS01460, AYJ09_RS01565) encoding hypothetical proteins, AYJ09_RS01495 encoding a transcriptional regulator, possibly a repressor, and AYJ09_RS01585, encoding a DUF2815 domain-containing protein (Supplementary Table S6). Only two genes (AYJ09_RS01560 and AYJ09_RS05440) encoding phagerelated hypothetical proteins had high expression levels. AYJ09_RS01560 has homologs in the other $\mathrm{Ca}$. Liberibacter species, and AYJ09_RS05440 has homologs in the other haplotypes of ' $\mathrm{Ca}$. L. solanacearum'.

By hierarchical clustering, clusters of ' $\mathrm{Ca}$. L. solanacearum' genes associated with either the early ( $5 \mathrm{wpi}$ ) or late ( $9 \mathrm{wpi}$ ) timepoint were identified (Fig. 4). Most of the genes in a cluster of 37 genes, more actively expressed at 5 wpi than at 9 wpi, were involved in transcription, translation, replication, or biosynthesis of fatty acids. Thirteen of these genes encode ribosomal proteins, and a highly expressed gene encoding a CarD family transcriptional regulator also was identified (Fig. 4A). In mycobacteria, CarD has been identified as an essential RNA polymerase modulator that regulates rRNA, pathogenesis, stress resistance, and growth (Stallings and Glickman 2011). Another interesting finding in this gene cluster is the gene AYJ09_RS03085 that is homologous to the nttA gene encoding an ATP translocase in ' $C a$. L. asiaticus', functioning in the uptake of ATP from the host cell cytoplasm (Vahling et al. 2010). A hypothetical gene AYJ09_RS04395, shown to be similar to the gene encoding a secreted HPE1 effector of ' $\mathrm{Ca}$. L. solanacearum' haplotypes A and B (Levy et al. 2020), was also among the ' $C a$. L. solanacearum' early genes. HPE1 was shown to inhibit the hypersensitive response-like cell death induced by an autoactive variant of a Prf resistance gene and Bax proapoptotic protein, suggesting that ' $C a$. L. asiaticus' and ' $C a$. L. solanacearum' may be able to interfere with the induction of ETI and cell death (Levy et al. 2020). Altogether, the ' $\mathrm{Ca}$. L. solanacearum' gene expression levels in carrot at the early timepoint suggest that the bacteria were actively replicating, transcribing, and translating, which is indicative of intensive growth of the bacteria in the plants at 5 wpi.

A cluster containing 42 genes with a higher expression level at 9 wpi than at 5 wpi included genes coding for peptidases and cell-wall proteins involved in secretion and transport. Genes coding for secretion system II proteins, signal peptidase, cation:proton antiporter, outer membrane protein assembly factor, and porin family protein were among the upregulated genes, suggesting that the bacterial cells interact actively with their environment. Expression of Flp pilus biosynthesis proteins, including Flp family type IVb pilin and two Flp pilus assembly proteins, $\mathrm{CpaB}$ and ATPase of CpaF family, was also up-regulated (Fig. 4B). Flp pilus, also called tight adherence (Tad) pilus, has been suggested to be involved in biofilm formation by ' $\mathrm{Ca}$. L. solanacearum' in the midguts of its vector potato psyllid (Cicero et al. 2016) and, by ' $C a$. L. asiaticus', in its vector Asian citrus psyllid (Andrade and Wang 2019). CpaF of 'Ca. L. asiaticus' was shown to be critical for bacterial adherence mediated by Tad pilus (Andrade and Wang 2019). In this study, the upregulation
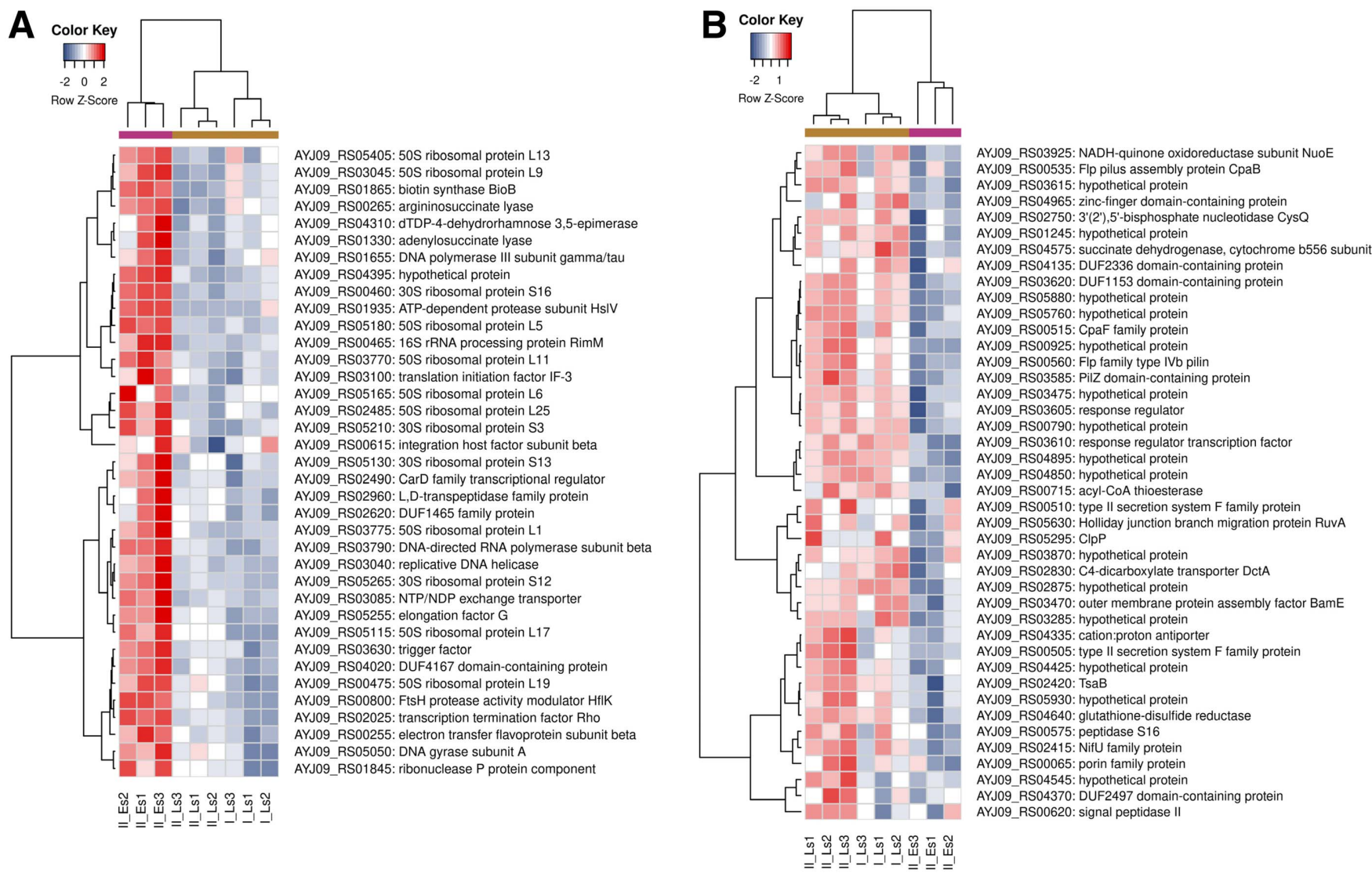

Fig. 4. Heatmaps of 'Candidatus Liberibacter solanacearum' gene expression levels $\log _{2}(\mathrm{TPM}+1)$ showing differences between the early and late timepoints. A, Genes that were more actively expressed at the early timepoint (5 weeks after inoculation), and $\mathbf{B}$, genes that were more actively expressed at the late timepoint (9 weeks after inoculation). Purple bar indicates the early timepoint samples (II_Es1, II_Es2, and II_Es3) and brown bar indicates the late timepoint samples (I_Ls1 to I_Ls3 and II_Ls1 to II_Ls3). The transcripts per million (TPM) values are scaled to Z-scores of rows. Each row represents a gene, and each column represents an RNA-Seq sample. 
of $c p a F$ and an $f p$ gene in 'Ca. L. solanacearum' at the late stage of infection in carrots suggests that Tad pilus may also have a function in planta. It is possible that the pilin encoded by one of the five loci (AYJ09_RS00560) was specifically recruited in the biogenesis of Tad pilus to attach to the plant sieve cell structures. At the late stage of infection, adherence instead of proliferation may promote bacterial survival. Genes involved in energy metabolism or membrane functions also showed increase in their relative expression levels at 9 wpi in comparison with 5 wpi, among them two genes encoding response regulators, a C4-dicarboxylate transporter DctA, and a succinate dehydrogenase (cytochrome b556 subunit).

The ' $C a$. L. solanacearum' gene encoding glucose major facilitator superfamily transporter was expressed at a high level at both 5 and 9 wpi, suggesting that ' $\mathrm{Ca}$. L. solanacearum' was constantly consuming glucose in the host plant. However, the expression patterns of the ' $\mathrm{Ca}$. L. solanacearum' genes encoding C4-dicarboxylate transporter and succinate dehydrogenase were correlated, and both were more actively expressed at the late timepoint. Both ' $\mathrm{Ca}$. L. solanacearum' and ' $\mathrm{Ca}$. L. asiaticus' are presumably able to uptake C4-dicarboxylates, including succinate, fumarate, oxaloaceate, and malate from the host cell cytoplasm, to use them as carbon sources in addition to glucose (Lin et al. 2011; Wang and Trivedi 2013). Moreover, it has been shown that either citrate or $\alpha$-ketoglutaric acid can be utilized as the primary carbon source by Liberibacter crescens, the only culturable Liberibacter species, when growing in an artificial culture medium (Cruz-Munoz et al. 2018; Sena-Vélez et al. 2019). The possibility that the other intermediates of the TCA cycle could also be imported via DctA cannot be ruled out. The carrot gene expression changes in the infected plants suggested an induction of the TCA cycle, which could have changed the C4-dicarboxylate concentrations. In citrus trees, decreased concentrations of malate and citrate were detected at the early stages of ' $\mathrm{Ca}$. L. asiaticus' infection, when the amount of bacteria was still low and no symptoms were visible (Liu et al. 2020). On the other hand, infection with ' $\mathrm{Ca}$. L. asiaticus' was shown to lead to the accumulation of several TCA cycle intermediates, citrate, succinate, and fumarate, while the concentration of 2-ketoglutaric acid was lower than in the controls (Nehela and Killiny 2019). The upregulation of ' $\mathrm{Ca}$. L. solanacearum' genes encoding C4-dicarboxylate transporter and succinate dehydrogenase at the late timepoint might be associated with adaptation to the physiological changes taking place in the infected carrot plants. In contrast, the expression level of the ' $C a$. L. solanacearum' ATP translocase was significantly higher at the early timepoint. These results suggest a change in the preference of the host-derived energy source between the early and late timepoints. At first, uptake ATP is preferred to satisfy the energy need of the multiplying cells, and later, possibly when the ATP resources have been depleted, the uptake of C4-dicarboxylates is increased.

\section{Validation of DEGs with real-time reverse transcription (RT)-PCR.}

Real-time RT-PCR was performed to validate 15 DEGs determined by the RNA-Seq data analyses; 12 DEGs of carrot, which were involved in cell wall, phloem occlusion, defense responses, hormone signaling, and secondary metabolism, and three DEGs of ' $\mathrm{Ca}$. L. solanacearum', involved in energy uptake and adhesion, were selected for the analysis. In general, the real-time RT-PCR results were consistent with the differential expression patterns detected by the RNA-Seq analyses (Fig. 5). The realtime RT-PCR confirmed that the expression patterns of four carrot genes, encoding flavone synthase, SEO, terpene synthase 10-like, and TIFY-10A like (JAZ1) were similar to the RNASeq results at all the timepoints (Fig. 5A). Upregulation of EDS1 and probable disease resistance protein At5g66910 was confirmed by real-time RT-PCR for all timepoints, and the genes encoding callose synthase 7-like and PR protein PR-1 type-like (PR-1) were found slightly upregulated already at $4 \mathrm{wpi}$, although they were not determined as DEGs at 4 wpi in the RNA-Seq data analyses. The elevated expression level of LysM domain receptor-like kinase 3 was confirmed by real-time RT-PCR at 5 and 9 wpi in the second experiment, whereas, in the first experiment, the variation was too large. Downregulation of chlorophyll a-b binding protein was only confirmed at 9 wpi in the first experiment. However, the trends of those two DEGs at 9 wpi were consistent between the two experiments. Downregulation of the transcription factors HY5 and MYC4 could only be validated at 4 wpi and at one of the 9-wpi timepoints, probably due to the relatively low expression levels of HY5 in all the samples and a small fold change in MYC4 (Supplementary Table S2). The realtime RT-PCR results for the selected ' $\mathrm{Ca}$. L. solanacearum' genes in the second experiment (Fig. 5B) agree with the result of hierarchical clustering analysis using the RNA-Seq data (Fig. 4). Thus, the differential expression patterns of the ' $C a$. L. solanacearum' genes encoding ATP translocase and CpaB (Fig. 5B) at the early and late timepoints of the second experiment were confirmed. For the first experiment 4-wpi samples, however, the cycle threshold $(\mathrm{Ct})$ values were high for both the reference genes $(\mathrm{Ct}$ from 29 to 32) and for the genes $C 4 d i$ ( $\mathrm{Ct}$ from 28 to 31 ) and $c p a B$ (Ct from 29 to 31 ), suggesting a low ' $\mathrm{Ca}$. L. solanacearum' titer and large variation between the samples, which collectively rendered the 4-wpi data poorly applicable for analyzing the ' $\mathrm{Ca}$. L. solanacearum' gene expression levels.

\section{Conclusions.}

The results of this study suggest a dynamic interaction between carrot, psyllids, and ' $\mathrm{Ca}$. L. solanacearum', as both the carrot and ' $\mathrm{Ca}$. L. solanacearum' genes showed different expression levels at the late stage of infection in comparison with the early stage. Many changes in the ' $\mathrm{Ca}$. L. solanacearum' gene expression are likely to reflect the different growth phases of the bacterial population in the phloem vessels or the adaptation of the bacteria to the changes in the host physiology. At the early stage of infection, the ' $\mathrm{Ca}$. L. solanacearum' gene expression profile was indicative of rapid growth, while, at the late stage, the expression of genes involved in protein secretion and attachment was enhanced. Four weeks after inoculation, the amount of bacteria was still low, and the plants were still responding to the psyllid feeding with induced production of volatile terpenoids, improved photosynthesis, and induction of JA production. With the multiplication of ' $\mathrm{Ca}$. L. solanacearum', the target of plant defense was switched to defense against the bacteria, including induced defense signaling and ETI and PTI responses (Fig. 5C). This change could suppress the defense against herbivory, potentially facilitating the psyllid feeding on the phloem sap of the infected plants. As a consequence of upregulation of the defenses, photosynthesis-related genes were down-regulated and catabolic processes were up-regulated in the heavily infected plants. This suggests that the infected plants used stored resources to satisfy the increased energy demand caused by the induced defense responses. The phenotypic changes observed at the late timepoint, discoloration of leaves and reduced root to foliage weight ratio, support the view that the resource allocation was modified in the infected plants from growth to defense.

\section{MATERIALS AND METHODS}

\section{Inoculation of carrot plants by carrot psyllid (Trioza apicalis) feeding.}

Two independent inoculation experiments were performed in controlled greenhouse environment. For the first experiment, 
performed during the summer 2014, the carrot psyllids (T. apicalis) used for inoculation had been collected in 2012 from a carrot field in Tavastia Proper region and, since then, had been reared in the laboratory. Twenty-nine 3-week-old carrot seedlings (cv. Fontana) at the two-leaf stage were individually enclosed in insect-proof cages, and 23 of them were exposed to two carrot psyllid females per seedling for 3 days, while six nonexposed seedlings were maintained as negative controls. After the exposure, carrot psyllids were manually removed from the cages. Then, the exposed and control carrot seedlings were grown in the greenhouse with temperature settings of $20^{\circ} \mathrm{C}$ during the day and $15^{\circ} \mathrm{C}$ at night, with $19 \mathrm{~h}$ of natural light in the first experiment and $20 \mathrm{~h}$ of light during the second experiment. Three weeks after inoculation, the third leaf of each exposed and nonexposed seedling was collected as a sample for testing the presence of ' $C a$. L. solanacearum' by PCR. For the second experiment, performed during the autumn 2015, new carrot psyllids were captured from a field in Tavastia Proper region in the summer and were reared in the laboratory, and psyllids from the F1 generation were used for inoculation. The experimental procedure was otherwise similar to that used in the first experiment, except that 21 carrot seedlings were exposed to psyllid feeding and eight seedlings were nonexposed controls and that the lights were on for $20 \mathrm{~h}$ per day to compensate for the smaller amount of natural light in the late autumn.

\section{Detection of ' $\mathrm{Ca}$. L. solanacearum' with real-time PCR.}

In order to confirm that the carrot seedlings exposed to psyllid feeding were infected with ' $\mathrm{Ca}$. L. solanacearum', the third leaf of each carrot seedling was taken as a sample 3 weeks after
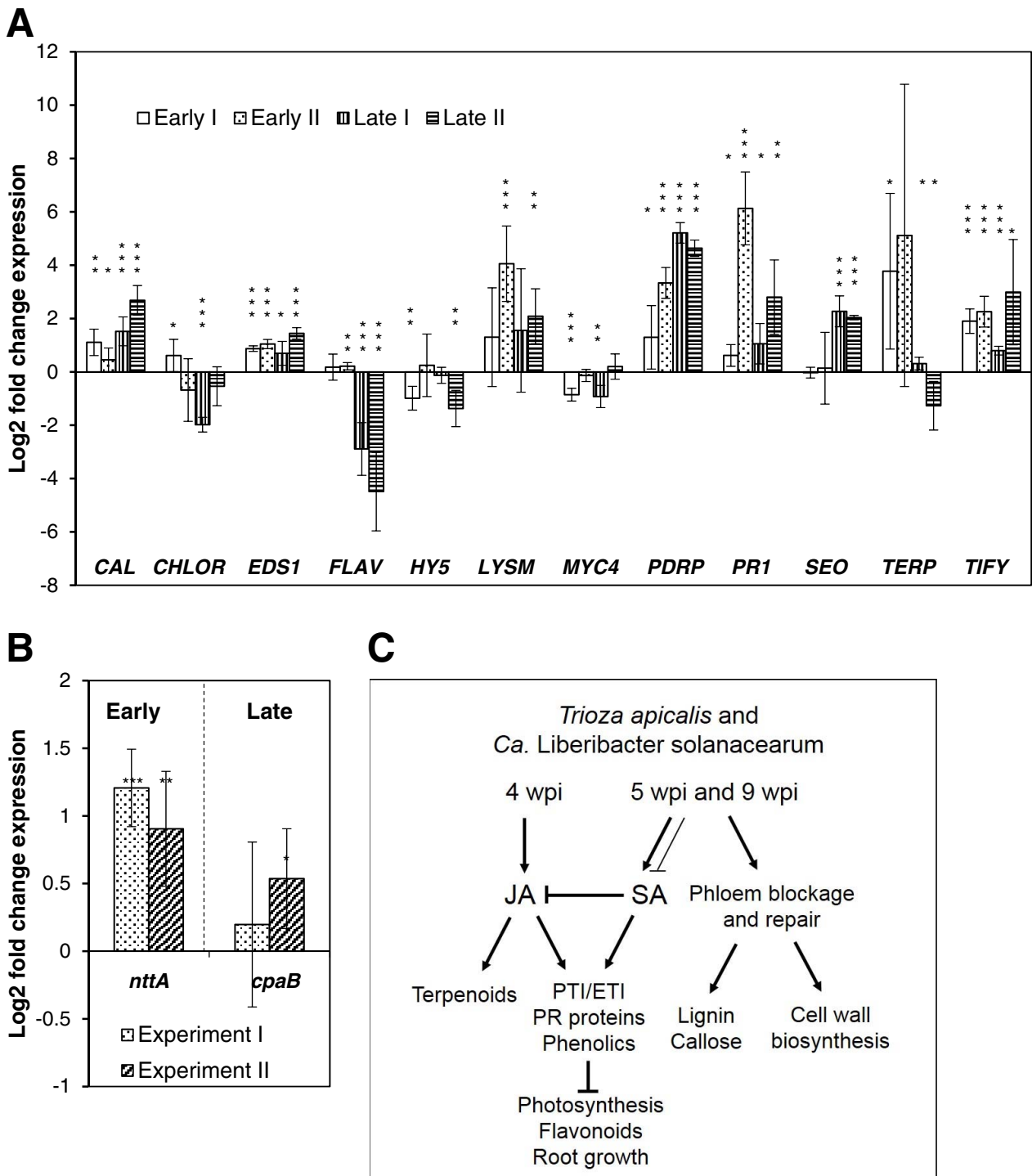

Fig. 5. Interaction between the carrot plant Trioza apicalis and 'Candidatus Liberibacter solanacearum' at the early and late stages of the infection, as revealed by changes in gene expression levels. A, Real-time PCR confirming the changes in gene expression levels in 'Ca. L. solanacearum'-infected carrot plants in comparison with the control plants at different timepoints. B, Real-time PCR confirming differentially expressed genes in ' $\mathrm{Ca}$. L. solanacearum' at the early and late timepoints. Genes analyzed: $C A L=$ callose synthase 7-like, $C H L O R=$ chlorophyll a-b binding protein, $E D S 1=E N H A N C E D$ DISEASE SUSCEPTIBILITY 1-like, FLAV = flavone synthase, HY5 = transcription factor, $L Y S M=$ LysM domain receptor-like kinase $3, M Y C 4=$ transcription factor, $P D R P=$ probable disease resistance protein At5g66910, $P R 1=$ pathogenesis-related protein PR1-like, $S E O=$ sieve element occlusion B-like, $T E R P=$ terpene synthase 10-like, $T I F Y=$ TIFY10A-like $(\mathrm{JAZ1}), n t t A=\mathrm{NTP} / \mathrm{NDP}$ exchange transporter (nttA-like), $c p a B=$ Flp pilus assembly protein. Error bars indicate the 95\% confidence interval of the mean, and asterisks indicate statistical significance determined by Student's $t$ test, with one asterisk (*) indicating $P<0.05$, two $\left(^{* *}\right) P<0.01$, and three $\left(^{* * *}\right) P<0.001$. C, An overview of the transcriptional changes in the ' $C a$. L. solanacearum'-infected carrot plants. Solid arrows indicate positive effects, blocked lines suggest negative effects, and the thin blocked arrow suggests a negative effect of ' $\mathrm{Ca}$. L. solanacearum' on plant defense. 
inoculation. Later, 200-mg samples for DNA extraction were taken of the carrots that were harvested for preparing RNA samples, one sample of the petioles (right above the part taken for RNA extraction) and another sample of the tip of the main root. At the late timepoint ( 9 wpi), DNA samples were taken of all the remaining carrot plants. DNA was extracted from the carrot samples by CTAB protocol as previously described (Nissinen et al. 2014). From the carrot psyllids used for the inoculation and thereafter removed from the plants, DNA was extracted, using a DNeasy blood and tissue kit (Qiagen, Hilden, Germany) according to manufacturer protocols, and was eluted in $30 \mu \mathrm{l}$ of water. The relative titer of ' $\mathrm{C} a$. L. solanacearum' in the plant and psyllid samples was determined by real-time PCR, using primers OA2 (Liefting et al. 2009) and LibRev153 (Nissinen et al. 2014) for ' $C a$. L. solanacearum' and primers DcITS-F and DcITS-R (Nissinen et al. 2014) for carrot. For the psyllid samples, primers OA2 and LibRev203 were used for detecting ' $\mathrm{Ca}$. L. solanacearum' and primers Tza-F2 and Tza-R2 (Nissinen et al. 2014) for the psyllid. Both the ' $\mathrm{Ca}$. L. solanacearum'-specific and reference gene reactions were done in triplicates. Reactions contained SYBR Green I master mix (Roche, Basel, Switzerland), $750 \mathrm{nM}$ primers, and $5 \mu \mathrm{l}$ of the DNA samples diluted 1:100 in water, in a $15-\mu 1$ reaction volume. PCR program $\left(95^{\circ} \mathrm{C}\right.$ for $5 \mathrm{~min}$ and 45 cycles of $95^{\circ} \mathrm{C}$ for $10 \mathrm{~s}, 54^{\circ} \mathrm{C}$ for $10 \mathrm{~s}$, and $72^{\circ} \mathrm{C}$ for $10 \mathrm{~s}$ ) was run with LightCycler 480 (Roche). For the psyllid samples, the efficiency of the real-time PCR reactions was $92 \%$ for both ' $\mathrm{Ca}$. L. solanacearum' $16 \mathrm{~S}$ and $T$. apicalis $18 \mathrm{~S}$ DNA, both with $R^{2}=0.99$. For the carrot samples, the efficiency of the realtime PCR reactions was $98 \%$ for ' $\mathrm{Ca}$. L. solanacearum' and $87 \%$ for carrot ITS 1 , both with $R^{2}=0.99$. The relative amount of ' $\mathrm{Ca}$. L. solanacearum' in each sample was calculated by Pfaffl's method (Pfaffl 2001).

\section{TEM.}

At the 9-wpi timepoint of the second experiment, samples of three ' $C a$. L. solanacearum'-infected carrots and a control carrot were prepared for TEM. Freshly cut 2-mm-wide pieces of carrot tissues were fixed in $2.5 \%$ glutaraldehyde in $0.1 \mathrm{M}$ sodium phosphate buffer with $2 \mathrm{mM} \mathrm{CaCl}_{2}$ at room temperature for $2 \mathrm{~h}$. The tissue samples were then placed in storage solution containing $2.0 \%$ formaldehyde and $2 \mathrm{mM} \mathrm{CaCl}{ }_{2}$ in $0.1 \mathrm{M}$ sodium phosphate buffer and were stored at $4{ }^{\circ} \mathrm{C}$. Before embedding, the tissue samples were treated with $1 \%$ osmium tetroxide, were washed with $0.1 \mathrm{M}$ sodium phosphate buffer, and were dehydrated with a graded series of ethanol. TEM samples were embedded in Epon resin, which was polymerized at $60^{\circ} \mathrm{C}$ overnight. Semithin sections stained with Toluidine blue were examined by light microscopy to locate the phloem tissues. Ultrathin sections of resinembedded samples were poststained with uranyl acetate and lead citrate. TEM was performed with a Jeol JEM-1400 microscope (Jeol Ltd., Tokyo) equipped with a Gatan Orius SC 1000B CCDcamera (Gatan Inc., Pleasanton, CA, U.S.A.).

\section{RNA extraction and sample preparation.}

In the first experiment, three carrot plants confirmed ' $\mathrm{Ca}$. L. solanacearum'-positive with similar $\mathrm{Ct}$ values at 3 wpi were selected for the early timepoint sampling at 4 wpi together with three noninoculated control plants. In the second experiment, the carrot sampling was changed from 4 to 5 wpi, because,e at 4 wpi, the ' $C a$. L. solanacearum' titer in the petiole samples was still too low for ' $C a$. L. solanacearum' RNA-Seq. In both experiments, the late timepoint RNA samples were prepared at 9 wpi of three inoculated carrot plants displaying leaf discoloration symptoms and three control plants. Of each plant, a 2.0-g sample of the lower ends of the petioles was cut immediately after weighing the root and the leaves, and was quickly frozen in liquid nitrogen. The samples were ground to powder in liquid nitrogen, and total RNA was extracted with Trizol reagent $(38 \%$ phenol ( $\mathrm{pH} 4.3$ ), $0.8 \mathrm{M}$ guanidine thiocyanate, $0.4 \mathrm{M}$ ammonium thiocyanate, $0.1 \mathrm{M}$ sodium acetate $(\mathrm{pH} 5.0), 5 \%$ glycerol), following the protocol by Rio et al. (2010). In short, after Trizol extraction the phenol was removed by chloroform extraction, and the RNA was precipitated from the aqueous phase with isopropanol, was washed with $75 \%$ ethanol, was partially air-dried, and was dissolved in $800 \mu \mathrm{l}$ of nucleasefree water, by incubating at $55^{\circ} \mathrm{C}$ for $10 \mathrm{~min}$. To further purify the RNA, half the sample volume of $8 \mathrm{M} \mathrm{LiCl}$ was added, and the RNA was precipitated overnight at $-20^{\circ} \mathrm{C}$. The precipitate was washed with $75 \%$ ethanol, was partially air-dried, and was dissolved in $500 \mu \mathrm{l}$ of nuclease-free water. The RNA samples were divided into $100-\mu 1$ aliquots and were stored at $-80^{\circ} \mathrm{C}$. Before sequencing, all the RNA samples were treated with DNase, and the sample quality was analyzed using the Agilent 2100 Bioanalyzer (Agilent Technologies, Santa Clara, CA, U.S.A.).

\section{RNA sequencing.}

In order to retain the meta-transcriptome of the carrot samples, mRNA purification with the polydT oligo was skipped and the total RNA samples were treated with Ribo-Zero rRNA removal kits (Illumina, San Diego, CA, U.S.A.) for plant and bacteria. ScriptSeq v2 RNA-Seq Library Preparation Kit (Illumina) was used for RNA sequencing library preparation of each RNA sample. The constructed libraries were purified with AMPure XP beads (Beckman Coulter, Indianapolis, IN, U.S.A.) and were sequenced using two flow-cells with Illumina NextSeq 500/550 platform for $2 \times 150$ cycles in the high output mode, which yields 80 million reads per sample on average. RNA sequencing libraries of all 24 samples were prepared and sequenced at the Functional Genomics Unit of the University of Helsinki, Finland. The raw RNA-Seq datasets have been deposited at the sequence read archive of the National Center for Biotechnology Information under the project number PRJNA574412.

\section{RNA-Seq data analysis.}

Adaptor and quality trimming of raw RNA-Seq datasets were performed using Trimmomatic v0.38 (Bolger at al. 2014). The carrot genome sequence assembly ASM162521v1 and the corresponding genome annotation were acquired from RefSeq (GCF_001625215.1). The trimmed pair-end reads of each sample were mapped to the reference genome using HISAT2 v2.1.0 (Kim et al. 2015). Since the organelle transcripts (chloroplast and mitochondria) were preserved in the RNA-Seq library construction, the organelle-derived reads were isolated from the meta-transcriptomic data by mapping to the carrot chloroplast (NC_008325.1) and mitochondria (NC_017855.1) genomes, respectively. Mapping results were converted to binary BAM format and were then sorted using Picard v2.23.6. The read count for each protein-coding gene was calculated by the htseqcount tool in HTSeq v0.11.2 (Anders et al. 2015). Differential expression between samples of inoculated and noninoculated plants at each timepoint in each experiment was determined using the R package DESeq2 v1.28.1 (Love et al. 2014). PCA and hierarchical clustering were performed for two experiments to examine the RNA sample clustering. Differential expression of chloroplast genes was analyzed separately from the nuclear genes. The DEGs were defined in each comparison with criteria of false discovery rate (FDR) below 0.05 . The GO annotations associated with genes in the carrot genome were acquired from UniProtKB, and the GO annotations of full version were mapped to the terms in the GO slim version for plants (available online) using the Map2Slim option in OWLTools. The KEGG Orthology of carrot (KEGG organism code dcr) genome genes was acquired from its corresponding BRITE hierarchy file. For 
the enrichment analyses of GO slim (plant) terms and KEGG pathways, two approaches were applied, including overrepresentation analysis with Fisher's exact test and the functional class scoring approach with gene set enrichment analysis, since both of the methods have limitations (Khatri et al. 2012). Results of the two approaches were combined. Both analyses were performed using the $\mathrm{R}$ package clusterProfiler v3.16.1 (Yu et al. 2012) with criteria of FDR below 0.1. The trimmed pair-end reads of each sample were also mapped to the ' $\mathrm{Ca}$. L. solanacearum' haplotype C FIN114 genome sequence ASM198367v1 (GCF_001983675.1). Similar procedures of read-pair mapping and mapped read-pair counting as above were performed with ' $\mathrm{Ca}$. L. solanacearum' genome, except for mapping read pairs using HISAT2 in no-spliced alignment mode (Supplementary Table S1). 'Ca. L. solanacearum' gene counts obtained of samples taken at 5 and 9 wpi were normalized into TPM (transcripts per million) (Wagner et al. 2012), and the genes with at least 30 TPM presented in more than five samples were defined as expressed genes. To determine the ' $\mathrm{Ca}$. L. solanacearum' genes differentially expressed between the early and late timepoints as groups, hierarchical clustering was performed. In addition, the mean-absolute-deviation of each gene was calculated prior to the clustering step, to retain those genes (the upper quartile) that showed drastically changed expression levels.

\section{RNA-Seq data validation using real-time RT-PCR.}

Real-time RT-PCR was used to validate some of the differential expression patterns detected in the RNA-Seq data. A portion of each RNA sample that was prepared for RNA-Seq was reserved for real-time RT-PCR. Two reference genes, actin-7 (ACT7) and serine/threonine protein phosphatase $2 A$ (PP2A), and 12 DEGs were selected for validation of differential expression between the infected and healthy carrot plants (Supplementary Table S7). Two reference genes, recA and ftsZ, and three DEGs were selected for validation of differential expression in ' $C a$. L. solanacearum' between the early and late timepoints. Quality control of RNA samples, DNase treatment, cDNA synthesis, and real-time PCR analyses were performed at the TATAA Biocenter (Göteborg, Sweden). Real-time PCR was performed using LightCycler 480 (Roche) with TATAA SYBR GrandMaster mix (TATAA Biocenter). Real-time RT-PCR data were preprocessed and analyzed with GenEx software (MultiD Analyses AB, Göteborg, Sweden). Comparisons between the expression levels of the selected genes in the infected and healthy carrots and in ' $C a$. L. solanacearum' at the early and late infection stage were conducted by Student's $t$ test $(P<0.05)$.

\section{ACKNOWLEDGMENTS}

We thank the Biomedicum Functional Genomics Unit (FuGU) at the University of Helsinki for RNA sequencing, S. Räsänen and S. Tuominen (Luke) and P. Lin for technical assistance, A. Strandell (Helsinki Institute of Life Science) for preparing the samples for TEM, M. Lindman for performing the electron microscopy at the Helsinki Institute of Life Science, TATAA Biocenter for performing the real-time analyses, Helsinki University Library for funding open access costs, and the CSC-IT Center for Science Ltd. Finland for providing computing services.

\section{AUTHOR-RECOMMENDED INTERNET RESOURCES}

Guide to GO subsets: http://geneontology.org/docs/go-subset-guide OWLTools: https://github.com/owlcollab/owltools/wiki/Map2Slim Picard: http://broadinstitute.github.io/picard/

\section{LITERATURE CITED}

Alvarado, V. Y., Odokonyero, D., Duncan, O., Mirkov, T. E., and Scholthof, H. B. 2012. Molecular and physiological properties associated with zebra complex disease in potatoes and its relation with
Candidatus Liberibacter contents in psyllid vectors. PLoS One 7 : e37345.

Anders, S., Pyl, P. T., and Huber, W. 2015. HTSeq-A Python framework to work with high-throughput sequencing data. Bioinformatics 31:166-169.

Andrade, M., and Wang, N. 2019. The Tad pilus apparatus of 'Candidatus liberibacter asiaticus' and its regulation by VisNR. Mol Plant-Microbe Interact. 32:1175-1187.

Antolinez, C. A., Fereres, A., and Moreno, A. 2017. Risk assessment of 'Candidatus Liberibacter solanacearum' transmission by the psyllids Bactericera trigonica and B. tremblayi from Apiaceae crops to potato. Sci. Rep. 7:45534.

Aritua, V., Achor, D., Gmitter, F. G., Albrigo, G., and Wang, N. 2013. Transcriptional and microscopic analyses of citrus stem and root responses to Candidatus Liberibacter asiaticus infection. PLoS One 8: e73742.

Bilgin, D. D., Zavala, J. A., Zhu, J., Clough, S. J., Ort, D. R., and DeLucia, E. H. 2010. Biotic stress globally downregulates photosynthesis genes. Plant Cell Environ. 33:1597-1613.

Bolger, A. M., Lohse, M., and Usadel, B. 2014. Trimmomatic: A flexible trimmer for Illumina sequence data. Bioinformatics 30:2114-2120.

Busta, L., Yim, W. C., LaBrant, E. W., Wang, P., Grimes, L., Malyszka, K., Cushman, J. C., Santos, P., Kosma, D. K., and Cahoon, E. B 2018. Identification of genes encoding enzymes catalyzing the early steps of carrot polyacetylene biosynthesis. Plant Physiol. 178:15071521.

Casteel, C. L., Hansen, A. K., Walling, L. L., and Paine, T. D. 2012. Manipulation of plant defense responses by the tomato psyllid (Bactericerca cockerelli) and its associated endosymbiont Candidatus Liberibacter psyllaurous. PLoS One 7:e35191.

Castel, B., Ngou, P. M., Cevik, V., Redkar, A., Kim, D. S., Yang, Y. Ding, P., and Jones, J. D. G. 2019. Diverse NLR immune receptors activate defence via the RPW8-NLR NRG1. New Phytol. 222:966980.

Chebli, Y., and Geitmann, A. 2017. Cellular growth in plants requires regulation of cell wall biochemistry. Curr. Opin. Cell Biol. 44:28-35.

Chen, L. Q., Hou, B. H., Lalonde, S., Takanaga, H., Hartung, M. L., Qu, X. Q., Guo, W. J., Kim, J. G., Underwood, W., Chaudhuri, B., Chermak, D., Antony, G., White, F. F., Somerville, S. C., Mudgett, M. B., and Frommer, W. B. 2010. Sugar transporters for intercellular exchange and nutrition of pathogens. Nature 468:527-532.

Chen, X., Yao, Q., Gao, X., Jiang, C., Harberd, N. P., and Fu, X. 2016. Shoot-to-root mobile transcription factor HY5 coordinates plant carbon and nitrogen acquisition. Curr. Biol. 26:640-646.

Chung, S. H., Rosa, C., Scully, E. D., Peiffer, M., Tooker, J. F., Hoover, K., Luthe, D. S., and Felton, G. W. 2013. Herbivore exploits orally secreted bacteria to suppress plant defenses. Proc. Natl. Acad. Sci U.S.A. 110:15728-15733.

Cicero, J. M., Fisher, T. W., and Brown, J. K. 2016. Localization of 'Candidatus Liberibacter solanacearum' and evidence for surface appendages in the potato psyllid vector. Phytopathology 106:142-154.

Cruz-Munoz, M., Petrone, J. R., Cohn, A. R., Munoz-Beristain, A., Killiny, N., Drew, J. C., and Triplett, E. W. 2018. Development of chemically defined media reveals citrate as preferred carbon source for Liberibacter growth. Front. Microbiol. 9:668.

Cui, H., Qiu, J., Zhou, Y., Bhandari, D. D., Zhao, C., Bautor, J., and Parker, J. E. 2018. Antagonism of transcription factor MYC2 by EDS1/ PAD4 complexes bolsters salicylic acid defense in Arabidopsis effector-triggered immunity. Mol. Plant 11:1053-1066.

Deng, H., Achor, D., Exteberria, E., Yu, Q., Du, D., Stanton, D., Liang, G., and Gmitter, F. G., Jr. 2019. Phloem regeneration is a mechanism for Huanglongbing-tolerance of "Bearss" lemon and "LB8-9" Sugar Belle ${ }^{\circledR}$ mandarin. Front. Plant Sci. 10:277.

Ding, Y., Sun, T., Ao, K., Peng, Y., Zhang, Y., Li, X., and Zhang, Y. 2018. Opposite roles of salicylic acid receptors NPR1 and NPR3/NPR4 in transcriptional regulation of plant immunity. Cell 173:1454-1467.e15.

Dong, O. X., Tong, M., Bonardi, V., El Kasmi, F., Woloshen, V., Wünsch, L. K., Dangl, J. L., and Li, X. 2016. TNL-mediated immunity in Arabidopsis requires complex regulation of the redundant ADRI gene family. New Phytol. 210:960-973.

Duan, Y., Zhou, L., Hall, D. G., Li, W., Doddapaneni, H., Lin, H., Liu, L., Vahling, C. M., Gabriel, D. W., Williams, K. P., Dickerman, A. Sun, Y., and Gottwald, T. 2009. Complete genome sequence of citrus huanglongbing bacterium, 'Candidatus Liberibacter asiaticus' obtained through metagenomics. Mol. Plant-Microbe Interact. 22: 1011-1020.

Dubois, M., Van den Broeck, L., and Inzé, D. 2018. The pivotal role of ethylene in plant growth. Trends Plant Sci. 23:311-323. 
Etxeberria, E., Gonzalez, P., Achor, D., and Albrigo, G. 2009. Anatomical distribution of abnormally high levels of starch in HLB-affected Valencia orange trees. Physiol. Mol. Plant Pathol. 74:76-83.

Fan, J., Hill, L., Crooks, C., Doerner, P., and Lamb, C. 2009. Abscisic acid has a key role in modulating diverse plant-pathogen interactions. Plant Physiol. 150:1750-1761.

Gatineau, F., Jacob, N., Vautrin, S., Larrue, J., Lherminier, J., RichardMolard, M., and Boudon-Padieu, E. 2002. Association with the syndrome "basses richesses" of sugar beet of a phytoplasma and a bacterium-like organism transmitted by a Pentastiridius sp. Phytopathology 92:384-392.

Granato, L. M., Galdeano, D. M., D’Alessandre, N. D. R., Breton, M. C., and Machado, M. A. 2019. Callose synthase family genes plays an important role in the Citrus defense response to Candidatus Liberibacter asiaticus. Eur. J. Plant Pathol. 155:25-38.

Grover, A. 2012. Plant chitinases: Genetic diversity and physiological roles. CRC Crit. Rev. Plant Sci. 31:57-73.

Haapalainen, M. 2014. Biology and epidemics of Candidatus Liberibacter species, psyllid-transmitted plant-pathogenic bacteria. Ann. Appl. Biol. 165:172-198.

Haapalainen, M., Kivimäki, P., Latvala, S., Rastas, M., Hannukkala, A., Jauhiainen, L., Lemmetty, A., Pirhonen, M., Virtanen, A., and Nissinen, A. I. 2017. Frequency and occurrence of the carrot pathogen 'Candidatus Liberibacter solanacearum' haplotype C in Finland. Plant Pathol. 66:559-570

Haapalainen, M., Latvala, S., Wickström, A., Wang, J., Pirhonen, M., and Nissinen, A. I. 2020. A novel haplotype of 'Candidatus Liberibacter solanacearum' found in Apiaceae and Polygonaceae family plants. Eur. J. Plant Pathol. 156:413-423.

Haapalainen, M., Wang, J., Latvala, S., Lehtonen, M. T., Pirhonen, M. and Nissinen, A. I. 2018. Genetic variation of 'Candidatus Liberibacter solanacearum' haplotype $\mathrm{C}$ and identification of a novel haplotype from Trioza urticae and stinging nettle. Phytopathology 108:925-934.

Hajri, A., Loiseau, M., Cousseau-Suhard, P., Renaudin, I., and Gentit, P. 2017. Genetic characterization of 'Candidatus Liberibacter solanacearum' haplotypes associated with apiaceous crops in France. Plant Dis. 101:1383-1390.

Han, X., Altegoer, F., Steinchen, W., Binnebesel, L., Schuhmacher, J., Glatter, T., Giammarinaro, P. I., Djamei, A., Rensing, S. A., Reissmann, S., Kahmann, R., and Bange, G. 2019. A kiwellin disarms the metabolic activity of a secreted fungal virulence factor. Nature 565:650-653.

Hansen, A. K., Trumble, J. T., Stouthamer, R., and Paine, T. D. 2008. A new huanglongbing species, "Candidatus Liberibacter psyllaurous," found to infect tomato and potato, is vectored by the psyllid Bactericera cockerelli (Sulc). Appl. Environ. Microbiol. 74:5862-5865.

Hijaz, F., Nehela, Y., and Killiny, N. 2016. Possible role of plant volatiles in tolerance against huanglongbing in citrus. Plant Signal. Behav. 11:e1138193.

Hinds, L., Kenny, O., Hossain, M. B., Walsh, D., Sheehy, E., Evans, P., Gaffney, M., and Rai, D. K. 2017. Evaluating the antibacterial properties of polyacetylene and glucosinolate compounds with further identification of their presence within various carrot (Daucus carota) and broccoli (Brassica oleracea) cultivars using high-performance liquid chromatography with a diode array detector and ultra performance liquid chromatography-tandem mass spectrometry analyses. J. Agric. Food Chem. 65:7186-7191.

Hu, Y., Zhong, X., Liu, X., Lou, B., Zhou, C., and Wang, X. 2017. Comparative transcriptome analysis unveils the tolerance mechanisms of Citrus hystrix in response to 'Candidatus Liberibacter asiaticus' infection. PLoS One 12:e0189229.

Huot, B., Yao, J., Montgomery, B. L., and He, S. Y. 2014. Growthdefense tradeoffs in plants: A balancing act to optimize fitness. Mol. Plant 7:1267-1287

Huot, O. B., Levy, J. G., and Tamborindeguy, C. 2018. Global gene regulation in tomato plant (Solanum lycopersicum) responding to vector (Bactericera cockerelli) feeding and pathogen ('Candidatus Liberibacter solanacearum') infection. Plant Mol. Biol. 97:57-72.

Ibanez, F., Levy, J., and Tamborindeguy, C. 2014. Transcriptome analysis of "Candidatus Liberibacter solanacearum" in its psyllid vector Bactericera cockerelli. PLoS One 9:e100955.

Iorizzo, M., Ellison, S., Senalik, D., Zeng, P., Satapoomin, P., Huang, J., Bowman, M., Iovene, M., Sanseverino, W., Cavagnaro, P., Yildiz, M., Macko-Podgórni, A., Moranska, E., Grzebelus, E., Grzebelus, D., Ashrafi, H., Zheng, Z., Cheng, S., Spooner, D., Van Deynze, A., and Simon, P. 2016. A high-quality carrot genome assembly provides new insights into carotenoid accumulation and asterid genome evolution. Nat. Genet. 48:657-666.
Jekat, S. B., Ernst, A. M., von Bohl, A., Zielonka, S., Twyman, R. M. Noll, G. A., and Prüfer, D. 2013. P-proteins in Arabidopsis are heteromeric structures involved in rapid sieve tube sealing. Front. Plant Sci. $4: 225$.

Khatri, P., Sirota, M., and Butte, A. J. 2012. Ten years of pathway analysis: Current approaches and outstanding challenges. PLOS Comput. Biol. 8:e1002375.

Kim, D., Langmead, B., and Salzberg, S. L. 2015. HISAT: A fast spliced aligner with low memory requirements. Nat. Methods 12:357-360.

Koh, E. J., Zhou, L., Williams, D. S., Park, J., Ding, N., Duan, Y. P., and Kang, B. H. 2012. Callose deposition in the phloem plasmodesmata and inhibition of phloem transport in citrus leaves infected with "Candidatus Liberibacter asiaticus". Protoplasma 249:687-697.

Lackman, P., González-Guzmán, M., Tilleman, S., Carqueijeiro, I., Pérez, A. C., Moses, T., Seo, M., Kanno, Y., Häkkinen, S. T., Van Montagu, M. C., Thevelein, J. M., Maaheimo, H., Oksman-Caldentey, K. M. Rodriguez, P. L., Rischer, H., and Goossens, A. 2011. Jasmonate signaling involves the abscisic acid receptor PYL4 to regulate metabolic reprogramming in Arabidopsis and tobacco. Proc. Natl. Acad. Sci. U.S.A. 108:5891-5896.

Lapin, D., Kovacova, V., Sun, X., Dongus, J. A., Bhandari, D., von Born, P., Bautor, J., Guarneri, N., Rzemieniewski, J., Stuttmann, J., Beyer, A., and Parker, J. E. 2019. A coevolved EDS1-SAG101-NRG1 module mediates cell death signaling by TIR-domain immune receptors. Plant Cell 31:2430-2455.

Laurema, S. 1989. Free amino acids in the psyllid Trioza apicalis Forst. (Homopt., Triozidae) and in carrot leaves. Ann. Agric. Fenn. 28:113120.

Lemonnier, P., Gaillard, C., Veillet, F., Verbeke, J., Lemoine, R., Coutos-Thévenot, P., and La Camera, S. 2014. Expression of Arabidopsis sugar transport protein STP13 differentially affects glucose transport activity and basal resistance to Botrytis cinerea. Plant Mol. Biol. 85:473-484

Levy, J. G., Gross, R., Mendoza-Herrera, A., Tang, X., Babilonia, K., Shan, L., Kuhl, J. C., Dibble, M. S., Xiao, F., and Tamborindeguy, C. 2020. Lso-HPE1, an effector of 'Candidatus Liberibacter solanacearum', can repress plant immune response. Phytopathology 110:648-655.

Levy, J. G., Mendoza, A., Miller, J. C., Jr., Tamborindeguy, C., and Pierson, E. A. 2017. Global gene expression in two potato cultivars in response to 'Candidatus Liberibacter solanacearum' infection. BMC Genomics 18:960.

Li, J., Pang, Z., Trivedi, P., Zhou, X., Ying, X., Jia, H., and Wang, N. 2017. 'Candidatus Liberibacter asiaticus' encodes a functional salicylic acid (SA) hydroxylase that degrades SA to suppress plan defenses. Mol. Plant-Microbe Interact. 30:620-630.

Li, Q., Fan, J., Sun, J., Zhang, Y., Hou, M., and Chen, J. 2019. Anti-plant defense response strategies mediated by the secondary symbion Hamiltonella defensa in the wheat aphid Sitobion miscanthi. Front. Microbiol. 10:2419.

Liefting, L. W., Weir, B. S., Pennycook, S. R., and Clover, G. R. G 2009. 'Candidatus Liberibacter solanacearum', associated with plants in the family Solanaceae. Int. J. Syst. Evol. Microbiol. 59:2274-2276.

Lin, H., Lou, B., Glynn, J. M., Doddapaneni, H., Civerolo, E. L., Chen, C., Duan, Y., Zhou, L., and Vahling, C. M. 2011. The complete genome sequence of 'Candidatus Liberibacter solanacearum', the bacterium associated with potato zebra chip disease. PLoS One 6: e19135.

Liu, L., Sonbol, F. M., Huot, B., Gu, Y., Withers, J., Mwimba, M., Yao, J., He, S. Y., and Dong, X. 2016. Salicylic acid receptors activate jasmonic acid signalling through a non-canonical pathway to promote effector-triggered immunity. Nat. Commun. 7:13099.

Liu, X., Grabherr, H. M., Willmann, R., Kolb, D., Brunner, F., Bertsche, U., Kühner, D., Franz-Wachtel, M., Amin, B., Felix, G., Ongena, M. Nürnberger, T., and Gust, A. A. 2014. Host-induced bacterial cell wall decomposition mediates pattern-triggered immunity in Arabidopsis. eLife 3:e01990.

Liu, Y., Xue, A., Ding, L., Hao, Y., Liu, H., Cui, M., Liu, L., Nie, Z., and Luo, L. 2020. Direct identification and metabolomic analysis of Huanglongbing associated with Candidatus Liberibacter spp. in navel orange by MALDI-TOF-MS. Anal. Bioanal. Chem. 412:30913101

Love, M. I., Huber, W., and Anders, S. 2014. Moderated estimation of fold change and dispersion for RNA-Seq data with DESeq2. Genome Biol. 15:550.

Major, I. T., Yoshida, Y., Campos, M. L., Kapali, G., Xin, X. F., Sugimoto, K., de Oliveira Ferreira, D., He, S. Y., and Howe, G. A. 2017. Regulation of growth-defense balance by the JASMONATE ZIM-DOMAIN (JAZ)MYC transcriptional module. New Phytol. 215:1533-1547. 
Marowa, P., Ding, A., and Kong, Y. 2016. Expansins: Roles in plant growth and potential applications in crop improvement. Plant Cell Rep. 35:949-965.

Mas, F., Vereijssen, J., and Suckling, D. M. 2014. Influence of the pathogen Candidatus Liberibacter solanacearum on tomato host plant volatiles and psyllid vector settlement. J. Chem. Ecol. 40:1197-1202.

Mauck, K. E., Sun, P., Meduri, V. R., and Hansen, A. K. 2019. New Ca. Liberibacter psyllaurous haplotype resurrected from a 49-year-old specimen of Solanum umbelliferum: A native host of the psyllid vector. Sci. Rep. 9:9530.

Michaeli, S., and Fromm, H. 2015. Closing the loop on the GABA shunt in plants: Are GABA metabolism and signaling entwined? Front. Plant Sci. 6:419.

Munyaneza, J. E., Fisher, T. W., Sengoda, V. G., Garczynski, S. F., Nissinen, A., and Lemmetty, A. 2010. First report of "Candidatus Liberibacter solanacearum" associated with psyllid-affected carrots in Europe. Plant Dis. 94:639.

Nehela, Y., Hijaz, F., Elzaawely, A. A., El-Zahaby, H. M., and Killiny, N. 2018. Citrus phytohormonal response to Candidatus Liberibacter asiaticus and its vector Diaphorina citri. Physiol. Mol. Plant Pathol. 102:24-35.

Nehela, Y., and Killiny, N. 2019. 'Candidatus Liberibacter asiaticus' and its vector, Diaphorina citri, augment the tricarboxylic acid cycle of their host via the $\gamma$-aminobutyric acid shunt and polyamines pathway. Mol. Plant-Microbe Interact. 32:413-427.

Nelson, W. R., Fisher, T. W., and Munyaneza, J. E. 2011. Haplotypes of "Candidatus Liberibacter solanacearum" suggest long-standing separation. Eur. J. Plant Pathol. 130:5-12.

Nissinen, A., Ibrahim, M., Kainulainen, P., Tiilikkala, K., and Holopainen, J. K. 2005. Influence of carrot psyllid (Trioza apicalis) feeding or exogenous limonene or methyl jasmonate treatment on composition of carrot (Daucus carota) leaf essential oil and headspace volatiles. J. Agric. Food Chem. 53:8631-8638.

Nissinen, A., Vanhala, P., Holopainen, J. K., and Tiilikkala, K. 2007. Short feeding period of carrot psyllid (Trioza apicalis) females at early growth stages of carrot reduces yield and causes leaf discolouration. Entomol. Exp. Appl. 125:277-283.

Nissinen, A. I., Haapalainen, M., Jauhiainen, L., Lindman, M., and Pirhonen, M. 2014. Different symptoms in carrots caused by male and female carrot psyllid feeding and infection by 'Candidatus Liberibacter solanacearum'. Plant Pathol. 63:812-820.

Nissinen, A. I., Haapalainen, M., Ojanen, H., Pirhonen, M., and Jauhiainen, L. 2020. Spreading of Trioza apicalis and development of 'Candidatus Liberibacter solanacearum' infection on carrot in the field conditions. Ann. Appl. Biol. 178:39-50.

Nissinen, A. I., Lemmetty, A., Pihlava, J.-M., Jauhiainen, L., Munyaneza, J. E., and Vanhala, P. 2012. Effects of carrot psyllid (Trioza apicalis) feeding on carrot yield and content of sugars and phenolic compounds. Ann. Appl. Biol. 161:68-80.

Nwugo, C. C., Sengoda, V. G., Tian, L., and Lin, H. 2017. Characterization of physiological and molecular processes associated with potato response to Zebra chip disease. Hortic. Res. 4:17069.

Okazaki, Y., and Saito, K. 2014. Roles of lipids as signaling molecules and mitigators during stress response in plants. Plant J. 79:584-596.

Parr, A. J., Ng, A., and Waldon, K. W. 1997. Ester-linked phenolic components of carrot cell walls. J. Agric. Food Chem. 45:2468-2471.

Paudel, J. R., and Bede, J. C. 2015. Ethylene signaling modulates herbivore-induced defense responses in the model legume Medicago truncatula. Mol. Plant-Microbe Interact. 28:569-579.

Pfaffl, M. W. 2001. A new mathematical model for relative quantification in real-time RT-PCR. Nucleic Acids Res. 29:e45.

Pichersky, E., and Raguso, R. A. 2018. Why do plants produce so many terpenoid compounds? New Phytol. 220:692-702.

Ravanbakhsh, M., Sasidharan, R., Voesenek, L. A. C. J., Kowalchuk, G. A., and Jousset, A. 2018. Microbial modulation of plant ethylene signaling: Ecological and evolutionary consequences. Microbiome 6 : 52.

Rio, D. C., Ares, M., Jr., Hannon, G. J., and Nilsen, T. W. 2010. Purification of RNA using TRIzol (TRI reagent). In: RNA: A Laboratory Manual. Sold Spring Harbor Laboratory Press, Cold Spring Harbor, NY, U.S.A

Rui, Y., Xiao, C., Yi, H., Kandemir, B., Wang, J. Z., Puri, V. M., and Anderson, C. T. 2017. POLYGALACTURONASE INVOLVED IN EXPANSION3 functions in seedling development, rosette growth, and stomatal dynamics in Arabidopsis thaliana. Plant Cell 29:24132432.

Schausberger, P. 2018. Herbivore-associated bacteria as potential mediators and modifiers of induced plant defense against spider mites and thrips. Front. Plant Sci. 9:1107.
Seljåsen, R., Vogt, G., Olsen, E., Lea, P., Høgetveit, L. A., Tajet, T. Meadow, R., and Bengtsson, G. B. 2013. Influence of field attack by carrot psyllid (Trioza apicalis Förster) on sensory quality, antioxidant capacity and content of terpenes, falcarindiol and 6-methoxymellein of carrots (Daucus carota L.). J. Agric. Food Chem. 61:2831-2838.

Sena-Vélez, M., Holland, S. D., Aggarwal, M., Cogan, N. G., Jain, M. Gabriel, D. W., and Jones, K. M. 2019. Growth dynamics and survival of Liberibacter crescens BT-1, an important model organism for the citrus Huanglongbing pathogen "Candidatus Liberibacter asiaticus". Appl. Environ. Microbiol. 85:e01656-19.

Sowden, R. G., Watson, S. J., and Jarvis, P. 2018. The role of chloroplasts in plant pathology. Essays Biochem. 62:21-39.

Stallings, C. L., and Glickman, M. S. 2011. CarD: A new RNA polymerase modulator in mycobacteria. Transcription 2:15-18.

Su, Q., Oliver, K. M., Xie, W., Wu, Q., Wang, S., and Zhang, Y. 2015. The whitefly-associated facultative symbiont Hamiltonella defensa suppresses induced plant defences in tomato. Funct. Ecol. 29:1007-1018.

Sumner-Kalkun, J. C., Highet, F., Arnsdorf, Y. M., Back, E., Carnegie, M., Madden, S., Carboni, S., Billaud, W., Lawrence, Z., and Kenyon, D. 2020. 'Candidatus Liberibacter solanacearum' distribution and diversity in Scotland and the characterisation of novel haplotypes from Craspedolepta spp. (Psyllidae: Aphalaridae). Sci. Rep. 10:16567.

Swisher Grimm, K. D., and Garczynski, S. F. 2019. Identification of a new haplotype of 'Candidatus Liberibacter solanacearum' in Solanum tuberosum. Plant Dis. 103:468-474.

Teresani, G. R., Bertolini, E., Alfaro-Fernández, A., Martínez, C., Tanaka, F. A., Kitajima, E. W., Roselló, M., Sanjuán, S., Ferrándiz, J. C., López, M. M., Cambra, M., and Font, M. I. 2014. Association of 'Candidatus Liberibacter solanacearum' with a vegetative disorder of celery in Spain and development of a real-time PCR method for its detection. Phytopathology 104:804-811.

Thompson, S. M., Johnson, C. P., Lu, A. Y., Frampton, R. A., Sullivan, K. L., Fiers, M. W. E. J., Crowhurst, R. N., Pitman, A. R., Scott, I. A. W., Wen, A., Gudmestad, N. C., and Smith, G. R. 2015. Genomes of 'Candidatus Liberibacter solanacearum' haplotype A from New Zealand and the United States suggest significant genome plasticity in the species. Phytopathology 105:863-871.

Thurow, C., Schiermeyer, A., Krawczyk, S., Butterbrodt, T., Nickolov, K., and Gatz, C. 2005. Tobacco bZIP transcription factor TGA2.2 and related factor TGA2.1 have distinct roles in plant defense responses and plant development. Plant J. 44:100-113.

Vahling, C. M., Duan, Y., and Lin, H. 2010. Characterization of an ATP translocase identified in the destructive plant pathogen "Candidatus Liberibacter asiaticus". J. Bacteriol. 192:834-840.

van Bel, A. J., Helariutta, Y., Thompson, G. A., Ton, J., Dinant, S., Ding, B., and Patrick, J. W. 2013. Phloem: The integrative avenue for resource distribution, signaling, and defense. Front. Plant Sci. 4: 471.

van Butselaar, T., and Van den Ackerveken, G. 2020. Salicylic acid steers the growth-immunity tradeoff. Trends Plant Sci. 25:566-576.

Wagner, G. P., Kin, K., and Lynch, V. J. 2012. Measurement of mRNA abundance using RNA-Seq data: RPKM measure is inconsistent among samples. Theory Biosci. 131:281-285.

Wallis, C. M., Rashed, A., Chen, J., Paetzold, L., Workneh, F., and Rush, C. M. 2015. Effects of potato-psyllid-vectored 'Candidatus Liberibacter solanacearum' infection on potato leaf and stem physiology. Phytopathology 105:189-198.

Wang, J., Haapalainen, M., Schott, T., Thompson, S. M., Smith, G. R., Nissinen, A. I., and Pirhonen, M. 2017. Genomic sequence of 'Candidatus Liberibacter solanacearum' haplotype C and its comparison with haplotype A and B genomes. PLoS One 12:e171531.

Wang, N., Pierson, E. A., Setubal, J. C., Xu, J., Levy, J. G., Zhang, Y., Li, J., Rangel, L. T., and Martins, J., Jr. 2017. The Candidatus Liberibacter-host interface: Insights into pathogenesis mechanisms and disease control. Annu. Rev. Phytopathol. 55:451-482.

Wang, N., and Trivedi, P. 2013. Citrus huanglongbing: A newly relevan disease presents unprecedented challenges. Phytopathology 103:652-665.

Wheeldon, C. D., and Bennett, T. 2021. There and back again: An evolutionary perspective on long-distance coordination of plant growth and development. Semin. Cell Dev. Biol. 109:55-67.

Xie, B., Wang, X., Zhu, M., Zhang, Z., and Hong, Z. 2011. CalS7 encodes a callose synthase responsible for callose deposition in the phloem. Plant J. 65:1-14.

Yamada, K., Saijo, Y., Nakagami, H., and Takano, Y. 2016. Regulation of sugar transporter activity for antibacterial defense in Arabidopsis. Science 354:1427-1430.

Yan, Q., Sreedharan, A., Wei, S., Wang, J., Pelz-Stelinski, K., Folimonova, S., and Wang, N. 2013. Global gene expression changes in 
Candidatus Liberibacter asiaticus during the transmission in distinct hosts between plant and insect. Mol. Plant Pathol. 14:391-404.

Yao, J., Saenkham, P., Levy, J., Ibanez, F., Noroy, C., Mendoza, A., Huot, O., Meyer, D. F., and Tamborindeguy, C. 2016. Interactions "Candidatus Liberibacter solanacearum"-Bactericera cockerelli: Haplotype effect on vector fitness and gene expression analyses. Front. Cell. Infect. Microbiol. 6:62.

Yoon, J., Choi, H., and An, G. 2015. Roles of lignin biosynthesis and regulatory genes in plant development. J. Integr. Plant Biol. 57: 902-912.
Yu, G., Wang, L. G., Han, Y., and He, Q. Y. 2012. clusterProfiler: An R package for comparing biological themes among gene clusters. OMICS 16:284-287.

Zhong, Y., Cheng, C. Z., Jiang, N. H., Jiang, B., Zhang, Y. Y., Wu, B., Hu, M. L., Zeng, J. W., Yan, H. X., Yi, G. J., and Zhong, G. Y. 2015 Comparative transcriptome and iTRAQ proteome analyses of citrus root responses to Candidatus Liberibacter asiaticus infection. PLoS One 10:e0126973.

Zhu, X., Chen, J., Qiu, K., and Kuai, B. 2017. Phytohormone and light regulation of chlorophyll degradation. Front. Plant Sci. 8:1911. 